\title{
Lytic bacteriophages facilitate antibiotic sensitization of Enterococcus faecium
}

6 Gregory S. Canfield, ${ }^{\mathrm{a}, \mathrm{b}}$ Anushila Chatterjee, ${ }^{\mathrm{b}}$ Juliel Espinosa ${ }^{\mathrm{c}}$, Mihnea R. Mangalea, ${ }^{\mathrm{b}}$ Emma K. Sheriff, ${ }^{\mathrm{b}}$

7 Micah Keidan, ${ }^{b}$ Sara W. McBride,,${ }^{b, *}$ Bruce D. McCollister, ${ }^{a}$, Howard C. Hang ${ }^{c, d}$ and Breck A. Duerkop ${ }^{b, \#}$

9 aDivision of Infectious Diseases, University of Colorado School of Medicine, Aurora, Colorado, USA

$10{ }^{b}$ Department of Immunology and Microbiology, University of Colorado School of Medicine, Aurora,

11 Colorado, USA

12 'Laboratory of Chemical Biology and Microbial Pathogenesis, The Rockefeller University, New York,

13 New York, USA.

14 dDepartments of Immunology \& Microbiology and Chemistry, Scripps Research, La Jolla, California, 15 USA.

16

17

18

19

20

21

22

23

6

\#Correspondence: Breck A. Duerkop breck.duerkop@cuanschutz.edu

*Current address: Salk Institute, La Jolla, California, USA

Running Title: Phages enhance antibiotic susceptibility of E. faecium

Key words: bacteriophages, Enterococcus, antibiotic resistance, phage-bacteria interactions, phage resistance, cephalosporin, beta-lactams 


\section{Abstract}

Enterococcus faecium, a commensal of the human intestine, has emerged as a hospitaladapted, multi-drug resistant (MDR) pathogen. Bacteriophages (phages), natural predators of bacteria, have regained attention as therapeutics to stem the rise of MDR bacteria. Despite their potential to curtail MDR E. faecium infections, the molecular events governing E. faecium-phage interactions remain largely unknown. Such interactions are important to delineate because phage selective pressure imposed on $E$. faecium will undoubtedly result in phage resistance phenotypes that could threaten the efficacy of phage therapy. In an effort to understand the emergence of phage resistance in E. faecium, three newly isolated lytic phages were used to demonstrate that $E$. faecium phage resistance is conferred through an array of cell wall-associated molecules, including secreted antigen $\mathrm{A}$ (SagA), enterococcal polysaccharide antigen (Epa), wall teichoic acids, capsule, and an arginineaspartate-aspartate (RDD) protein of unknown function. We find that capsule and Epa are important for robust phage adsorption and that phage resistance mutations in sagA, epaR, and epaX enhance $E$. faecium susceptibility to ceftriaxone, an antibiotic normally ineffective due to its low affinity for enterococcal penicillin binding proteins. Consistent with these findings, we provide evidence that phages potently synergize with cell wall (ceftriaxone and ampicillin) and membrane-acting (daptomycin) antimicrobials to slow or completely inhibit the growth of E. faecium. Our work demonstrates that the evolution of phage resistance comes with fitness defects resulting in drug sensitization and that lytic 
Introduction.

Enterococci are intestinal commensal bacteria and important opportunistic human pathogens

57

58

59

60

61

62

63

64

65

66

67

68

69

(1). Of the two most clinically relevant enterococcal species, Enterococcus faecalis and Enterococcus

faecium, the emergence of multidrug resistance is observed most commonly with $E$. faecium (2).

Considering that effective antibiotics with activity against multidrug-resistant (MDR) E. faecium are limited, clinicians are often forced to use antibiotic combination therapy to treat these infections (3). Although this approach can be life-saving, these regimens increase the risk of patient adverse drug events, drug-drug interactions, dysbiosis, and may fail to cure the infection (4). Rising from desperate treatment dilemmas like these are several examples of the successful use of phage therapy to treat MDR bacterial infections in humans (5-8). These success-stories have motivated renewed interest in the use of phage therapy for treatment of bacterial infections. Despite this motivation, relatively little is understood about the bacterial receptors exploited by phages to infect their bacterial hosts and the counter-measures employed by bacteria to avoid phage infection. We believe that understanding the molecular events that lead to phage resistance in MDR bacteria may help mitigate the threat of phage therapy failure.

Recently, our group and others have begun to elucidate the molecular mechanisms that enable successful phage infection of enterococci and the bulk of these studies were performed for $E$. faecalis and its interactions with tailed dsDNA phages (8-15). The molecular mechanisms enabling phage infection in E. faecium are poorly understood. Our knowledge of potential E. faecium phage receptors comes from an in vitro study where the co-existence of phages and $E$. faecium was studied through multiple passages in laboratory media (12). Whole genome sequencing of phage resistant survivors showed mutations in the capsule tyrosine kinase ywqD2 (equivalent to wze), RNA polymerase $\beta$ subunit $(r p o C)$, several predicted hydrolases, and a cell wall precursor enzyme. It was proposed that these mutations conferred phage resistance, though direct genetic testing of this hypothesis was not performed. Tandem-duplications in a putative phage tail fiber gene (EFV12PHI1_98) supported evolution of phages that overcame adaptive changes that resulted in phage resistance of $E$. faecium (12). 
In this work, we expand on our understanding of phage-enterococcal interactions by identifying

genes important for lytic phage infection of clade B strains of E. faecium. We have isolated three

previously uncharacterized E. faecium-specific phages and show that each belong to the Siphoviridae morphotype of the Caudovirales and resemble previously described lytic enterococcal phages (9-11,

14). Protein coding sequence comparison to other enterococcal phages reveals that one phage belongs to a novel enterococcal phage orthocluster and the remaining two phages belong to previously described enterococcal phage orthoclusters (16). To identify the molecular determinants of E. faecium phage infection, we used these three phages to generate a collection of $E$. faecium phage resistant mutants. Phage resistance mutations mapped to genes encoding the cell wall hydrolase secreted antigen A (sagA), putative teichoic acid precursors of the enterococcal polysaccharide antigen (epa), capsule biosynthesis enzymes, and an arginine-aspartate-aspartate (RDD) protein of unknown function. Capsule and putative teichoic acid biosynthesis proteins were shown to influence phage adsorption. Considering that all of the genes identified are involved in cell wall biochemistry and/or architecture, we determined if these phage resistance mutations result in fitness tradeoffs that lead to altered antimicrobial susceptibility. Phage resistant strains harboring mutations in sagA, epaX, and epaR showed enhanced susceptibility to cell wall and/or membrane-acting antibiotics, including ceftriaxone, ampicillin, and daptomycin. We discovered that combining phages with cell wall or membrane-acting antimicrobials acts synergistically to inhibit the growth of $E$. faecium. These findings suggest lytic phages might be leveraged as antibiotic adjuvants to offset the emergence of multi-drug

\section{Results.}

104 Genome sequence analysis and morphology of novel lytic E. faecium bacteriophages. E. 105 faecium phages 9181,9183 and 9184 were isolated from raw sewage by plaque assay using $E$. 106 faecium clade B strains Com12 and 1,141,733 (17). We chose to focus on clade B strains (commensal107 associated) given reports that these strains can serve as a reservoir for transmission of multidrug 108 resistance plasmids to clade A1 (hospital-associated) strains (18). Evaluation of phage morphology by 
TEM revealed that all three phages were non-contractile tailed phages characteristic of the Siphoviridae morphotype (Fig. 1) (19). DNA sequence analysis demonstrated that the phage 9181, 9183 and 9184 genomes are 71,854bp, 86,301bp, and 44,601bp in length, respectively (Fig. 1). The genomes of phages 9181 and 9183 were assembled into single contigs. The phage 9184 genome assembled into two contigs, with a 53-bp sequencing gap located near the 5' end of a predicted BppU-family phage baseplate upper protein. In total, 123, 128, and 73 open reading frames (ORFs) were identified for phages 9181,9183 and 9184, respectively (Table S1). Genome modularity based on predicted gene function was observed for each phage genome, however, for phage 9181 the lysin and holin genes are located at the $5^{\prime}$ and 3 ' termini of the genome (Fig. 1). Functional classifications, consisting of replication or biosynthesis, DNA packaging, phage particle morphogenesis, nucleic acid restriction and modification, host cell lysis, sensory function, sugar transferase and a potential $\beta$-lactamase, could be predicted for approximately $30 \%, 47 \%$, and $48 \%$ of the phage 9181,9183 , and 9184 ORFs, respectively (Table S1). The remaining genes were predicted to be hypothetical genes or genes containing domains of unknown function. A PCR screen for phage lysogeny in phage-resistant $E$. faecium mutants failed to identify phage 9181,9183 , and 9184 DNA integration within their respective E. faecium host genomes (Table 1; Fig. S1). These data are consistent with a lack of phage DNA among genomic reads from phage 9181,9183 , and 9184 -resistant $E$. faecium mutants and the absence of turbid plaques, a feature often attributed to lysogenic phages. Together, these data indicate that phage 9181,9183 , and 9184 are most likely obligate lytic phages when preying on $E$. faecium Com12 or $1,141,733$.

\section{Comparative genome analysis places phages 9181,9183 , and 9184 in distinct orthoclusters.}

Comparative genome analysis of phages 9181,9183 and 9184 was performed with all publicly available enterococcal phage genomes using OrthoMCL, an algorithm that identifies clusters of orthologous proteins from at least two phages enabling phylogenetic categorization of phage proteins into orthoclusters $(16,20)$. Of the 10 enterococcal phage orthoclusters originally identified by Bolocan et al. (16), OrthoMCL clustering places phage 9184 into orthocluster I and phage 9183 into orthocluster 
X (Fig. 2). Phage 9181 forms a new orthocluster that we have named orthocluster XI (Fig. 2). Whole genome alignments of phages 9183 and 9184 to their nearest orthocluster neighbors, VPE25 and VFW for 9183 and vB_EfaS-DELF1 and IME-EFm5 for 9184, revealed conserved protein sequence identity and similar genome organization (Fig. S2A and S2B). Conversely, phage 9181 shared little protein sequence identity and genome organization to its nearest neighbors, phage EFC-1 and phage FL4A, supporting its placement as the sole member of a new orthocluster (Fig. S2C). Higher protein sequence identity and more similar genome organization was observed for phages belonging to the same orthocluster rather than phages belonging to different orthoclusters. Since the publication of Bolocan et al., an additional 45 phage genomes have been made publically available, resulting in the identification of a $12^{\text {th }}$ orthocluster consisting of phages EFA-1 and EFA-2, two recently described phages of unknown morphology (Fig. 2). Consistent with prior observations of orthocluster I phages, a $\beta$ lactamase domain-containing protein (ORF35) was found in the genome of phage 9184 (Fig. 1 and Table S1C). Similar to phages in orthocluster $X$, an integrase-family recombinase was found in the genome of phage 9183 (Table S1B). However, prior evidence demonstrates that other members of this orthocluster are unable to lysogenize their $E$. faecalis host (11), which is consistent with absence of lysogenized phage 9183 in phage 9183 resistant mutants as mentioned above (Fig. S1B).

\section{E. faecium phages have broad and narrow tropism for laboratory and clinical $E$. faecium}

isolates. We next sought to determine the host range of each phage against strains of E. faecium and E. faecalis. To achieve this, a phage susceptibility assay was performed by spotting 10-fold seriallydiluted enterococcal cultures on Todd-Hewitt broth (THB) agar embedded with phages 9181,9183 or 9184. A panel of 10 laboratory E. faecium isolates and 11 contemporary MDR clinical E. faecium isolates were selected for this analysis (Table S4) (17). An E. faecium strain was considered phagesusceptible if less than $1 \times 10^{5} \mathrm{CFU} / \mathrm{mL}$ were recovered following phage exposure, representing greater than 4-log of bacterial killing. Phages 9181 and 9183 demonstrated narrow host ranges against laboratory E. faecium strains (Fig. 3A). Besides the host strain on which the phage was isolated (Com12 for phage 9181 and 1,141,733 for phage 9183), only E. faecium Com15 was susceptible to 
163 phage 9181, while no other E. faecium laboratory strain tested was susceptible to phage 9183.

164 Contrarily, $60 \%$ of the laboratory E. faecium strains were susceptible to phage 9184 , including clade A 165 and B strains (Fig. 3A). There was an absence of susceptibility to phage 9181 and 9183 , and reduced 166 susceptibility ( 36\%) to phage 9184 for the contemporary MDR clinical E. faecium isolates (Fig. 3B).

167 Efficiency of plaquing assay revealed that phages 9181 and 9184 most efficiently plaqued on their 168 respective host strains (Fig. 3C-D). Together these data show that phage 9184 has a broader host 169 range compared to phages 9181 and 9183 and that these phages plaque most efficiently on their $E$. 170 faecium host strains, a likely byproduct of repeated phage propagation on the same strain (21). 171 Interestingly, E. faecium 1,231,501 and 1,230,933, the latter of which is a multi-drug resistant clade A strain, lacked susceptibility to phage 9181,9183 and 9184 . None of the three phages were capable of infecting any of the 10 clinical E. faecalis strains tested (designated UCH12-20 in Table S4), suggesting that these phages are specific for E. faecium.

Phage predation elicits spontaneous and stable phage resistance in $E$. faecium. To identify $E$. faecium genes that are involved in phage infection, we isolated spontaneous phage-resistant $E$. faecium strains following exposure to phages 9181,9183 and 9184 . Phage-resistant isolates were identified by plating stationary phase cultures of E. faecium Com12 and 1,141,733 on THB agar embedded with phages 9181,9183 , or 9184 . Colonies that arose on these plates represented potential phage-resistant colonies. To confirm the stability of the phage-resistant phenotype, a colony was serially passaged daily for 3 days on THB agar before re-streaking again on phage embedded THB agar. The growth of a strain in the presence of phage following serial passage suggested a stable phage-resistant phenotype (Fig. 4A-C). Six to eight independent phage-resistant strains were further characterized for phages 9181, 9183 and 9183 (Table 1 and Table S2). For phages 9181 and 9183 resistant E. faecium strains (denoted 81R3-8 and 83R1-8, respectively) we observed bacterial growth in 187 the presence of phages to levels that were similar to bacterial growth in the absence of phages 188 indicating a strong resistance phenotype (Fig. 4A, 4B and Fig. S3A, S3B, S3D, S3E). However, for 189 phage 9184 we observed limited phage resistance in all but one presumed $E$. faecium phage resistant 
isolate (Fig. 4C and Fig. S3C, S3F) suggesting that robust resistance to phage 9184 may be multifactorial.

\section{E. faecium phage resistance mutations occur in cell wall biosynthesis and architecture genes}

194 and a gene encoding a transmembrane protein. To identify genetic changes conferring a phage 195 resistance phenotype, we performed whole genome DNA sequencing of phage resistant and parental 196 E. faecium strains. We observed unique and conserved genome mutations in strains that had 197 developed phage resistance (Fig. 5A-D and Table S2A-C).

Five of six mutations identified in phage 9181-resistant strains were detected in efvg_rs16270, which in the $E$. faecium Com 12 reference genome is annotated as a hypothetical protein and was flanked by a 5' sequencing gap. Closure of this sequencing gap by PCR and amplicon sequencing revealed that efvg_rs16270 encodes the E. faecium secreted antigen A (SagA) protein. Whole genome sequencing showed that all sagA mutations localized at or near the peptidoglycan clamp or active site residues of the NIpC_P60 hydrolase domain of SagA, which was recently shown to function as an endopeptidase that cleaves crosslinked Lys-type peptidoglycan fragments (Fig. 5A and Table S2A) (22). To determine the impact of sagA mutations on protein structure and function, each single nucleotide polymorphism-associated sagA mutant was assessed by Missense 3D analysis (23). BLASTp alignment of SagA from E. faecium Com12 and Com15 showed 95\% identity along the entire length of the protein and E. faecium Com12 and Com15 exhibit identical protein homology in the NIpC_P60 hydrolase domain (Fig. S4A), suggesting that SagA should be functionally conserved between these two stains. Therefore, we used the E. faecium Com15 NIpC_P60 crystal structure (PDB $6 \mathrm{~B} 8 \mathrm{C}$ ) in Missense 3D to assess the impact of residue changes on the structure and function of 214 growing $\left(\mathrm{OD}_{600} \sim 0.8\right)$ wild type and sagA mutants, we performed Western blots for SagA expression. All 215 sagA mutants produced similar levels of both intracellular and secreted SagA suggesting that these $216 \operatorname{sag} A$ mutants are likely catalytically inactive or dampened because of mutations in the NIpC_P60 
217 hydrolase domain (Fig. S4B, S4C, and S4D). We then complemented the sagA mutations in phage

2189181 resistant strains using a construct previously generated, pAM401-sagA, which carries the sagA

219 gene and its native promoter from E. faecium Com15 (24). For all sagA mutants, complementation

220 with pAM401-sagA restored phage susceptibility (Fig. S5A). These results suggest that SagA

221 hydrolase activity may be dispensable for E. faecium viability and that non-crosslinked peptidoglycan in

222 E. faecium Com12 is important for phage 9181 infection.

223 One phage 9181-resistant strain (81R7) harbored mutations in capsule tyrosine kinase (wze)

224 and topoisomerase III (topB) genes and lacked a sagA mutation (Table S2A). Similarly, sequencing

225 analysis of all 9184 resistant strains (84R1-6) revealed an assortment of mutations in the capsule

226 biosynthesis locus. Nonsense, insertion and deletion mutations were detected in wze, capsule

227 aminotransferase (efsg_rs08090), capsule polymerase (wzy), and capsule nucleotide sugar

228 dehydrogenase (efsg_rs08120) genes (Fig. 5B and Table S2C). Prior co-evolution experiments

229 between the Myoviridae phage 1 and E. faecium TX1330 revealed a propensity for wze mutations

230 within an evolved phage resistant E. faecium population (12). Our data is consistent with this

231 observation and suggests that E. faecium capsule might serve as a possible receptor and/or adsorption

232 factor for phage 9181 and 9184 . We found that complementation of certain capsule mutants, using the

233 constitutive expression vector pLZ12A (i.e. 84R2 with efsg_rs08120 and 84R5 with efsg_rs08090),

234 partially restored phage 9184 susceptibility, while complementation of other capsule mutants (i.e. 84R6

235 and 81R7 each with wze) failed to restore phage susceptibility (Fig. S5B-C). This result suggests that

236 capsule is not a major factor mediating phage resistance to phage 9181 (Fig. S5B) and only weakly

237 promotes phage 9184 resistance when select capsule genes are mutated (Fig. S5C). These results

238 emphasize the importance of other non-capsule associated mutations in conferring phage-resistance to

239 phage $9181(\operatorname{sag} A)$ and phage $9184(r d d)$. We attempted to address the non-capsule associated

240 mutation in strain 81R7 (topB) and its involvement in phage 9181 resistance, however, all attempts to

241 clone topB into the pLZ12A resulted in truncated topB inserts following transformation into Escherichia

242 coli, suggesting that constitutive expression of E. faecium topB may be toxic to E. coli. Similarly, to

243 address the role of the non-capsule mutation detected in 84R6, which exhibited a robust phage 9184- 
244 resistance phenotype, a predicted arginine-aspartate-aspartate gene $(r d d)$, this gene was successfully 245 cloned into pLZ12A yet transformation of this construct into E. faecium 84R6 was unsuccessful despite 246 repeated attempts. Given the ease with which pLZ12A-wze and empty pLZ12A vector were

247 transformed into E. faecium 84R6 and our repeated failure to successfully recover transformants 248 harboring pLZ12A-rdd suggests that over-expression of rdd in E. faecium 84R6 may be lethal. epaR and epaX (Fig. 5D and Table S2B). Mutation of epaR and epaX results in E. faecalis phage resistance $(9,10,14)$ and recently it was determined that the epaR and epaX genes of E. faecalis V583 participate in wall teichoic acid biosynthesis (25). Considering that mutation of the epaX homologs epaOX and epaOX2 from E. faecalis OG1RF conferred phage VPE25-resistance by limiting phage adsorption $(10,11)$, we suspect that teichoic acids also mediate adsorption of phage 9183 to $E$. faecium 1,141,733. We were surprised that we did not find any phage 9183 resistant strains with mutations in $\mathrm{PIP}_{\mathrm{EF}}$, given the high protein homology and similar genome organization observed

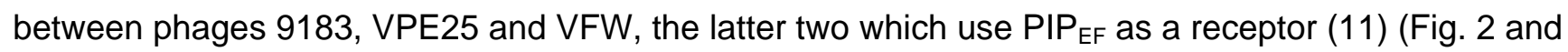
Fig. S2A). To confirm that mutations in the epa locus confer phage resistance in E. faecium, we pursued a similar complementation strategy as above with the epaR and epaX mutants identified in the phage 9183-resistant mutants. All phage 9183-resistant mutants complemented with either the epaR or epaX were restored for phage susceptibility (Fig. S5D). Given the importance of D-alanylation in teichoic acid biosynthesis, we performed complementation with pLZ12A-dltA in the epaX and dltA double mutant (83R7). We observed that only pLZ12A-epaX, not pLZ12A-dltA, was capable of restoring phage susceptibility in $83 \mathrm{R} 7$ (Fig. S5D). Considering that EpaX acts upstream of DItA in the biosynthesis of teichoic acids (25), these data suggest that dltA is dispensable during phage infection, lending further support to the notion that the epa variable locus involved in teichoic acid biosynthesis is 267 a driver of $E$. faecium infection by phage 9183. 
271 adsorption to wild type and phage resistant $E$. faecium strains using a phage adsorption assay $(9,10$, 14). For phage 9181 resistant strains, we observed no significant change in percentage adsorption to 273 sagA mutant strain 81R5, nor phage resistant strain $81 \mathrm{R} 7$ harboring a wze and topB mutations (Fig.

$2746 \mathrm{~A})$. These results are consistent with the inability of wze complementation to enhance phage 9181 275 adsorption in $81 \mathrm{R} 7$ (Fig. S6A). This result suggests that mutation of wze in E. faecium Com12 has little 276 to no effect on phage 9181 adsorption. Given that SagA is expressed into supernatants of phage 9181 277 resistant sagA mutants, it remains possible that phage 9181 adsorbs to SagA or non-crosslinked 278 peptidoglycan at the surface of E. faecium Com12. Furthermore, it is possible that complementation of 279 topB in the $81 \mathrm{R} 7$ background might cause transcriptional or translational changes in surface expressed 280 molecules enabling enhanced phage 9181 adsorption phenotype (Fig. 6A). Unfortunately, the lack of a 281 sag $A$ knock-out mutant and topB complementation vector prevented us from addressing these 282 questions.

Previous work has demonstrated that epa mutants exhibit phage adsorption defects in $E$. faecalis $(9,10,13,14)$. Since we observed epa mutations that conferred phage 9183 resistance, we sought to determine if epa mutations might promote a similar phenotype in E. faecium. We observed a reduction in phage 9183 adsorption to mutants possessing epaR (83R6 and 83R8) and epaX (83R4 and 83R7) mutations compared with the parental strain (Fig. 6B). Although epaX mutants 83R4 and $83 R 7$ were noted to also have mutations in $g d h$ and $d l t A$, respectively, we suspect that EpaX was the driver of this phenotype because of the known role of epaX homolog mutations to inhibit phage VPE25 adsorption to E. faecalis and that EpaX functions upstream of DItA in the biosynthesis of teichoic acid $(10,25)$. Consistent with this notion, we observed that over-expressing epaR and epaX in phage 9183 resistant mutants, $83 \mathrm{R} 3$ and $83 \mathrm{R} 4$, harboring mutations in epaR and epaX regained the ability to adsorb phage 9183 (Fig. S6B). Taken together, these results suggest that mutations in the epa locus of 294 E. faecium lessen phage 9183 adsorption to the surface of its host strain.

To determine if mutations in the capsule locus facilitated phage 9184 adsorption defects, we 296 performed phage 9184 adsorption assays using wild type and phage 9184 resistant mutants. We 297 observed significant deficits in phage adsorption to strains harboring mutations in capsule polymerase 
(wzy; 84R1), nucleotide sugar dehydrogenase (efsg_rs08120; 84R4), aminotransferase (efsg_rs08090;

84R5) and tyrosine kinase (wze; 84R6) in comparison to the parental strain (Fig. 6C).

300 Complementation of 84R2 with efsg_rs08120 restored phage 9184 adsorption, while complementation

301 of 84R6 with wze partially restored phage 9184 absorption, albeit the change was statistically non-

302 significant compared to the empty vector control strain (Fig. S6C). Given that $84 \mathrm{R} 6$ also harbors an rdd 303 mutation which encodes a putative transmembrane protein, we cannot definitively conclude that the 304 adsorption deficit was related to the wze mutation, as this wze mutation did not cause an adsorption 305 defect for phage 9181 (Fig. 6A and Fig. S6A). Considering the adsorption defect is greater for the 306 capsule mutants raised against phages 9184 compared to the phage 9181 capsule mutant $81 \mathrm{R} 7$, it is 307 possible that additional surface associated molecules mediate the attachment of phage 9181 to $E$. 308 faecium cells. Together, these data indicate that E. faecium capsule contributes to phage 9184 309 adsorption and may be phage specific.

E. faecium phage resistance enhances $\beta$-lactam and lipopeptide susceptibility. With renewed

interest focused on utilizing lytic phages for the treatment of bacterial infections and the observation that phage resistance can be a fitness tradeoff under antibiotic pressure $(26,27)$, we sought to determine the impact of $E$. faecium phage resistance on antimicrobial susceptibility. We performed antimicrobial susceptibility screening using E-test strips for the phage 9181, 9183, and 9184 resistant mutants compared to their parental strains to determine if phage resistance altered $E$. faecium antimicrobial susceptibility. For phage 9181 resistant mutants, we observed a $\sim 2-5$ fold reduction in the minimum inhibitory concentration (MIC) of ampicillin and an overall reduction in the MIC of ceftriaxone (Table S3A). Interestingly, the enhancement of ampicillin and ceftriaxone susceptibility correlated with phage 9181 resistant mutants harboring mutations in $s a g A$, and not wze or topB. For phage 9183 resistant mutants, we also observed a 3-5 fold reduction in the MIC of ampicillin and an overall reduction in the MIC of ceftriaxone (Table S3B). Additionally, we noted a 2.5-5 fold reduction in the MIC of daptomycin, a lipopeptide class antimicrobial, which was not observed for the phage 9181 or 9184 resistant mutants. These results suggest that the acquisition of phage resistance via mutation of 
sag $A$ and epa genes in $E$. faecium is a fitness defect that manifests as enhanced $\beta$-lactam susceptibility. lactams or lipopeptides, suggesting that mutations to the E. faecium capsule locus and rdd avoid the cost of increased antimicrobial susceptibility to $\beta$-lactams and daptomycin (Table S3C).

\section{Lytic phages synergize with $\beta$-lactam and lipopeptide antimicrobials to inhibit the growth of $E$.}

faecium. Considering the antibiotic fitness cost associated with phage resistance in E. faecium, we hypothesized that phages 9181 and 9183 would be capable of synergizing with ampicillin, ceftriaxone, and daptomycin to inhibit the growth of E. faecium. To address this question, we performed phageantibiotic synergy assays where E. faecium was grown in the presence of phages alone, sub-inhibitory concentrations of ampicillin, ceftriaxone, or daptomycin alone, or a combination of phage and a subinhibitory concentration of antibiotics (Fig. 7A-E). For all three antibiotics, we observed that the combination of phage and sub-inhibitory concentrations of antibiotics were able to inhibit the growth of E. faecium better than phage or antibiotic alone. Given the absence of growth inhibition of $E$. faecium in the presence of sub-inhibitory concentrations of antibiotics alone, this result is consistent with a synergistic antimicrobial interaction between phages and antibiotics. Interestingly, the synergy observed between phages 9181 and 9183 and ceftriaxone appeared more potent than the synergy observed between these phages and ampicillin (Fig. 7A-D). A dose-response relationship emerged when ampicillin was combined with phages 9181 and 9183 where decreasing concentrations of ampicillin enabled varying degrees of bacterial population recovery (Fig. 7A-B). These data suggest that phages 9181 and 9183 could serve as useful adjuvants in combination with $\beta$-lactams for the treatment of $E$. faecium infections by restoring the susceptibility to $E$. faecium strains harboring intrinsic $\beta$-lactam resistance. We also observed that the combination of phage 9183 and daptomycin slowed the growth of E. faecium 1,141,733 more than phage 9183 alone or daptomycin alone (Fig. 7E). This suggests that phage 9183 also synergizes with daptomycin to inhibit $E$. faecium $1,141,733$. These results are consistent with those observed by Morrisette et al. who observed synergy between the 
bioRxiv preprint doi: https://doi.org/10.1101/2020.09.22.309401; this version posted January 27, 2021. The copyright holder for this preprint

(which was not certified by peer review) is the author/funder, who has granted bioRxiv a license to display the preprint in perpetuity. It is made available under aCC-BY-NC-ND 4.0 International license.

352

Myoviridae phage 113 and $\beta$-lactam (ampicillin, ertapenem and ceftaroline) and lipopeptide antimicrobials against daptomycin-resistant and tolerant strains of E. faecium (28).

\section{Discussion.}

Considering the treatment pitfalls due to worsening drug resistance in E. faecium and other bacterial pathogens, the biomedical community is revisiting the use of phage therapy. Since phage therapy's departure from $20^{\text {th }}$ century Western Medicine, new technologies have emerged that have facilitated fine-scale resolution of phage-bacterial molecular interactions. Despite these advancements, for many bacteria, including E. faecium, the molecular factors exploited by phages for infection remain largely understudied (12). We believe that studying the molecular interactions of phages with their $E$. faecium hosts will inform rational approaches for future phage therapies against this pathogen.

In this work, we describe three novel lytic phages of E. faecium. Using protein coding orthology, we show that one of these phages, phage 9181 , forms a new orthocluster from the ten previously described enterococcal phage orthoclusters (16). We show that these phages are specific for $E$. faecium and exhibit broad and narrow strain tropism. Using whole genome sequencing and comparative genomics, we provide evidence that sagA, epa, and capsule biosynthesis genes are important for phage infection of $E$. faecium. We were unable to fully assess if the genes topB and $r d d$ are important in conferring phage 9181 and phage 9184 resistance, respectively. We suspect that these genes aid in phage-E. faecium interactions. Consistent with previous observations in $E$. faecalis $(9,10,13,14)$, we show that mutations in epaR and epaX limit phage 9183 adsorption to $E$. faecium, albeit to a lesser extent than that observed for similar mutations in E. faecalis. For example, the difference in phage VPE25 adsorption to wild type E. faecalis versus an epaOX mutant was $~ 80 \%$ (10), compared with the $\sim 35 \%$ reduction in phage 9183 adsorption to an epaX (epaOX homolog) mutant (Fig. 6B). This weaker phage 9183 adsorption despite the inability to infect the host closely resembles the $\sim 50 \%$ reduction in phage SHEF2 adherence to an epaB and OPDV_11720 (encoding an epaX-like glycosyltransferase) mutants compared to wild type $E$. faecalis $(29,30)$. The partial adsorption of phage 9183 to epaR and epaX mutants despite phage resistance suggests that phage 9183 adherence might 
also depend on the core Epa rhamnopolysaccharide, in addition to Epa teichoic acid decorations, similar to phage SHEF2 (29). We show for the first time that mutations in the capsule locus, which is absent in E. faecalis (17), limits phage 9184 adsorption to E. faecium 1,141,733, but not phage 9181 adsorption to $E$. faecium Com 12 . The $~ 50 \%$ reduction in phage 9184 adsorption in capsule mutants (Fig. 6C), is comparable to the $\sim 60-80 \%$ reduction of phages Ycsa and 8 against acapsular

Streptococcus thermophilus (31).

Our investigation into fitness tradeoffs associated with $E$. faecium phage resistance revealed enhanced susceptibility to cell wall and membrane-acting antibiotics. We demonstrated that phages 9181 and 9183 synergize with cell wall and membrane-targeting antibiotics to more potently inhibit $E$.

faecium. Importantly, this analysis revealed that phages 9181 and 9183 could sensitize E. faecium to ceftriaxone, an antibiotic that normally promotes enterococcal colonization of the intestine due to intrinsic resistance (32). Phage synergy with ceftriaxone is an important discovery as it suggests a strategy to re-sensitize enterococci to a third-generation cephalosporin. Exposure to cell wall-acting agents is recognized as a key event prior to hospital-acquired enterococcal infection in susceptible patients and cephalosporin re-sensitization could have a broad impact on anti-enterococcal therapy $(2$, 33). Cephalosporin activity pressures the native intestinal microbiota altering its ecology and related mucosal immunity, creating a scenario for enterococci to thrive and become dominant members of the microbiota (33-36). In patients with weakened immune systems or made vulnerable from hospital procedures such as surgeries, bone marrow ablative chemotherapy, or pre-existing alcoholic hepatitis/cirrhosis, these ceftriaxone-associated conditions can tip the scale in favor of infection (33-35, 37, 38). Even in E. faecium strains with ampicillin susceptibility, synergy with ceftriaxone for the treatment of endocarditis was demonstrated to be not absolute, suggesting that current Infectious Disease Society of America guidelines for the treatment of E. faecium endocarditis may lead to suboptimal results $(39,40)$. Combination therapy with phage and cell wall or membrane-acting antimicrobials may offer a potential solution to circumvent this issue, while avoiding the risk associated with exposing patients to combination $\beta$-lactam agents. 
The underlying molecular mechanisms conferring enhanced susceptibility to beta-lactams in sagA, epaR and epaX mutants remain unclear. Given that intrinsic resistance of $E$. faecium to

407 ceftriaxone is derived, in part, from class A and B penicillin binding proteins (Pbps) (41-44), we 408 hypothesize that modification of the surface architectural display of Pbps in epaR, epaX, and sagA 409 mutants might facilitate this phenotype. Parallels to E. faecium sagA mutants can be drawn from 410 mutation of a secreted peptidoglycan hydrolase in E. faecalis, SalB, which also demonstrates enhanced 411 susceptibility to cephalosporins (45). Pairwise amino acid alignment of E. faecium Com12 SagA and E. 412 faecalis SalB revealed $51 \%$ identity over the $\mathrm{N}$-terminal coiled-coil domain region, which is expected 413 given their different C-terminal hydrolase domains (SCP in SalB; NIpC_P60 in SagA). Contrary to sagA 414 in E. faecium, salB was shown to be non-essential in E. faecalis, and has a homolog (salA) which may 415 partly compensate for the function of salB to maintain cell viability (45). Staining of an $E$. faecalis salB 416 mutant with a non-specific, fluorescent penicillin (Bocillin FL) revealed no difference from wild type.

417 However, this analysis was performed in the absence of ceftriaxone pre-treatment, potentially masking 418 subtle changes in the abundance of Pbps in the salB mutant at the cell wall (41). Therefore, it remains 419 unclear if SalB partners with or coordinates the activity of Pbps to induce cephalosporin resistance. A $\operatorname{sag} A$ mutant described in our study (81R5; G460D) has a mutation residing two residues upstream 421 from a peptidoglycan clamp residue (W462) and lacked enhanced susceptibility to ampicillin and ceftriaxone. The reason for this exception and why this mutation confers phage resistance is unclear. The enhanced susceptibility to $\beta$-lactams in epaR and epaX in E. faecium mutants was surprising given prior reports of increased $\beta$-lactam resistance in epa mutants in E. faecalis (46). However, we note that all epa mutants tested in that analysis harbored mutations in genes from the core region of epa locus (i.e. epaA, epaE, epaL, epaN, epaB). To the best of our knowledge, this is the first report demonstrating enhanced $\beta$-lactam sensitivity to epa variable region mutants in enterococci. We observed enhanced susceptibility to daptomycin in E. faecium epaR and epaX mutants, consistent with data from $E$. faecalis epaR and epaX mutants $(9,14,47)$. Given that the epa variable genes have recently been discovered to be involved in teichoic acid biosynthesis (25), we hypothesize that altered display of teichoic acids at the cell surface enables the differential $\beta$-lactam and daptomycin 
432 susceptibility observed in epa core versus variable region mutants in enterococci. This hypothesis is

433 supported by observations in Staphylococcus aureus, where metabolic perturbations leading to

434 enhanced teichoic acid output or teichoic acid D-alanylation correlate with daptomycin tolerance (48-

435 50). Similarly, mutation of $l a f B$, a gene encoding lipoteichoic acid glycosyltransferase, induces a

436 daptomycin hypersusceptible phenotype in E. faecium (51). Mutation of bgsB in E. faecalis, which

437 functions with a lafB homolog (bgsA) in lipoteichoic acid anchor biosynthesis, results in enhanced

438 susceptibility to daptomycin (14). A reduction in susceptibility to the $\beta$-lactam piperacillin in lafB (E.

439 faecium) or $\operatorname{bgsB}$ (E. faecalis) mutants is reminiscent of the effect of epa core region mutations in

440 enterococci (46). A similar pattern of enhanced daptomycin susceptibility at the cost of reduced $\beta$ -

441 lactam susceptibility, known as the see-saw effect (52), suggests that the altered display or abundance

442 of the wall teichoic acids at the cell surface may occur in response to the modification of

443 rhamnopolysaccharide or lipoteichoic acid. Mutation of epaR or epaX in E. faecium would potentially

444 avoid the daptomycin- $\beta$-lactam see-saw effect, making phages that induce these mutations in

445 enterococci attractive antimicrobial candidates. Collectively, these observations suggest that the

446 location of epa mutations, core versus variable region, as well mutations in genes participating in

447 teichoic acid biosynthesis, are likely to impact the trajectory of $\beta$-lactam and daptomycin susceptibility in 448 enterococci.

E. faecalis epa mutations are detrimental during intestinal colonization and show reduced

virulence in a mouse peritonitis infection model $(9,53,54)$. epa mutants are more susceptible to bile salts, neutrophils, exhibit reduced biofilm formation, and are unable to invade biotic and abiotic surfaces $(47,54-56)$. Therefore, we predict that epaR and epaX mutants in E. faecium will show a similar intestinal colonization dysfunction. Hydrolase-domain mutations in SagA are also likely to induce fitness costs in vivo. SagA was shown to promote E. faecium attachment to multiple connective tissue molecules, including fibrinogen, fibronectin, and collagen (57). Interestingly, peptidoglycan fragments 456 released following SagA hydrolytic activity activates NOD2-mediated mucosal immunity in the intestine, 457 providing protection from Salmonella enterica infection and Clostridioides difficile pathogenesis (22, 458 24). In E. faecalis, mutation of the sagA-like gene salB altered cell morphology, increased biofilm 
459 formation, impacted autolysis, and increased susceptibility to bile salts, detergent, ethanol, peroxide, 460 and heat (58-61). Contrary to SagA, cells expressing SalB were limited in binding fibronectin and 461 collagen type I, suggesting that these proteins exhibit different adherence capacities to host tissue.

462 Considering these observations together, it is possible that phage predation that promotes the 463 formation of sagA mutants would result in E. faecium cells that are compromised for adherence and/or 464 invasion of host tissues, and potentially less immunostimulatory during infection. The absence of phage-antibiotic synergy for phage resistant strains harboring capsule, topoisomerase $3(t o p B)$, and the rdd gene does not imply that these mutations do not come with a fitness cost for other antimicrobial agents. We selectively chose to examine beta-lactams and daptomycin in this study given their clinical relevance for treating enterococcal infections. Sensitization to other antibiotics that target pathways other than cell wall biogenesis or membrane stability may exist and remain to be tested. The presence of phage-antibiotic synergy might be a function of how a

471 mutation inhibits phage infection. For instance, bacterial mutations that limit phage adsorption and/or genome ejection (i.e. epa, sagA) into the host cell might result in sensitivity to agents acting at the cell wall or membrane, while mutations that might inhibit phage genome replication (i.e. top $B$ ) could sensitize cells to agents that block bacterial DNA replication. Sensitization of $E$. coli to novobiocin, a 475 topoisomerase inhibitor, following mutation of topB (a type I topoisomerase) supports this theory (62). 476 Additionally, purified capsule from Streptococcus pneumoniae was shown to protect an acapsular 477 mutant of Klebsiella pneumoniae from polymyxin B (63), a lipopeptide antibiotic that normally binds 478 lipopolysaccharide in the outer membrane of Gram-negative bacteria (64). E. faecalis epa variable 479 locus mutants are also sensitized to polymyxin B (30), suggesting phage resistance sensitizes 480 enterococci to other antibiotics for which they exhibit intrinsic resistance (64).

Although phage-antibiotic synergy represents an enticing approach for treatment of multi-drug resistant $E$. faecium infections, the narrow host range observed for phages 9181 and 9183 (Fig. 3A-B) 483 will need to be addressed in future studies. Ideal phages would exhibit broader host range activity while 484 retaining synergy with antibiotics. Whether such phages exist in the natural environment is unclear. If 
485 not, phage recombineering methods offer promise for precisely broadening the host range of phages $486(65-67)$ E. faecium clade B. The inability of phage 9183 to infect $E$. faecium Com12 despite this strain exhibiting a near identical epa locus compared to 1,141,733 (i.e. epa variant 2) $(17,18)$, suggests phage 9183 might adsorb to Com12 but is unable to infect the cell either due to an inability to bind a secondary receptor, intracellular restriction, or failure to effectively lyse the cell following intracellular phage replication and assembly. What drives phage 9181 specificity for E. faecium Com12 and Com15, but not 1,141,733 is not clear. Given the near identical SagA amino acid sequences between

E. faecium Com 12 and 1,141,733 (Identity 97\%, Positives 97\%, Gaps $2 \%$ ) suggests that architecture of

495 the peptidoglycan or a mechanism highlighted above for phage 9183 resistance enable E. faecium $1,141,733$ resistance to phage 9181 infection. Future studies will seek to identify further host factors that constrain the host range of these phages. loci between the strains infected by phage 9184 , it is difficult to ascertain an attribute of this loci that might serve as a determinant of phage 9184 adsorption and infectivity. Acknowledging that the arginine-aspartate-aspartate (RDD) protein has yet to be proven as a receptor for phage 9184 , the conservation of this protein in E. faecium Com12, which is not infected by phage 9184, suggests that RDD is not the factor limiting infection of this strain.

506 cell surface to be critical for productive phage infection. The enhanced sensitivity of sagA, epaR and 507 epaX mutants to cell wall and membrane acting antimicrobials suggests that these proteins represent 508 intriguing antimicrobial targets to be considered for future drug discovery efforts against E. faecium, and 509 potentially other Gram-positive pathogens harboring homologs of these genes. The finding that $E$. 510 faecium phages synergize with $\beta$-lactam and lipopeptide antibiotics provides encouragement that 
511 phages could be used in combination with these antibiotics to increase their efficacy and possibly

512 repurpose such antibiotics that are currently deemed ineffective against enterococci.

\section{Materials and Methods.}

515 Bacteria and bacteriophages. A complete list of the bacterial strains and bacteriophages used in this 516 study can be found in Table S4. E. faecium Com12 was cultured in Todd-Hewitt broth (THB) and E. 517 faecium $1,141,733$ was cultured in brain heart infusion $(\mathrm{BHI})$ broth at $37^{\circ} \mathrm{C}$ with rotation at $250 \mathrm{rpm}$. $E$. 518 coli strains were cultured in Lennox $\mathrm{L}$ broth $(\mathrm{LB})$ at $37^{\circ} \mathrm{C}$ with rotation at $250 \mathrm{rpm}$. Semi-solid media in 519 petri plates were made by adding $1.5 \%$ agar to broth prior to autoclaving. For antibiotic susceptibility testing, Mueller Hinton Broth (MHB) was used. When needed, chloramphenicol was added to media at $20 \mu \mathrm{g} / \mathrm{ml}$ or $10 \mu \mathrm{g} / \mathrm{ml}$ for selection of $E$. coli or E. faecium, respectively. Phage susceptibility assays

Bacteriophage isolation and purification. Phages 9181,9183 , and 9184 were isolated from wastewater obtained from a water treatment facility located near Denver, Colorado. Fifty milliliters of raw sewage was centrifuged at $3220 \times g$ for 10 minutes at room temperature to remove debris. The supernatant was decanted and passed through a $0.45 \mu \mathrm{m}$ filter. A $100 \mu \mathrm{l}$ aliquot of filtered wastewater was mixed with $130 \mu \mathrm{l}$ of $E$. faecium $1,141,733$ or Com12 diluted 1:10 from an overnight culture and incubated at room temperature for $15 \mathrm{~min}$. Molten THB top agar (0.35\%), supplemented with $10 \mathrm{mM}$ $\mathrm{MgSO}_{4}$, was added to the bacteria-wastewater suspension and poured over a $1.5 \%$ THB agar plate supplemented with $10 \mathrm{mM} \mathrm{MgSO}_{4}$. Following overnight growth at $37^{\circ} \mathrm{C}$, plaques were picked with a sterile Pasteur pipette and phages were eluted from the plaque in $500 \mu \mathrm{l}$ SM-plus buffer $(100 \mathrm{mM} \mathrm{NaCl}$, $50 \mathrm{mM}$ Tris- $\left.\mathrm{HCl}, 8 \mathrm{mM} \mathrm{MgSO}_{4}, 5 \mathrm{mM} \mathrm{CaCl}_{2}[\mathrm{pH} 7.4]\right)$ overnight $(\mathrm{O} / \mathrm{N})$ at $4^{\circ} \mathrm{C}$. After $\mathrm{O} / \mathrm{N}$ elution, the phages were filter sterilized $(0.45 \mu \mathrm{m})$. This procedure was repeated two more times to ensure clonal phage isolates. To amplify phages to high titer stocks, 10 -fold serially diluted clonal phage isolates were mixed with their appropriate host strain diluted 1:10 from an $\mathrm{O} / \mathrm{N}$ culture, incubated at room temperature and then poured over $1.5 \%$ THB agar supplemented with $10 \mathrm{mM} \mathrm{MgSO}_{4}$. Top agar from 
538 multiple near confluent lysed bacterial lawns were scraped into a $15 \mathrm{ml}$ conical tube and centrifuged at

$53918000 \times g$ for 10 minutes prior to decanting and $0.45 \mu \mathrm{m}$ filter sterilization. Using these recovered

540 phages, high-titer phage stocks were generated by infecting $500 \mathrm{~mL}$ of early logarithmically $\left(2-3 \times 10^{8}\right.$

$541 \mathrm{CFU} / \mathrm{mL}$ ) growing E. faecium with phage at a multiplicity of infection of 0.5 following supplementation of

542 media with $10 \mathrm{mM} \mathrm{MgSO}_{4}$. The phage-cell suspension was incubated at room temperature for $15 \mathrm{~min}$

543 and then incubated at $37^{\circ} \mathrm{C}$ with rotation $(200 \mathrm{rpm})$ for $4-6$ hours. The cultures were centrifuged at

$5443220 \times g$ for 10 minutes at $4^{\circ} \mathrm{C}$ and the supernatants filtered $(0.45 \mu \mathrm{m})$. Clarified and filtered lysates

545 were treated with $5 \mu \mathrm{g} / \mathrm{ml}$ each of DNase and RNase at room temperature for 1 hour and phages were

546 precipitated with $1 \mathrm{M} \mathrm{NaCl}$ and $10 \%$ (wt/vol) polyethylene glycol 8000 (PEG 8000) on ice at 4ํㅡ

547 overnight. Phage precipitates were pelleted by centrifugation at $11,270 \times g$ for 20 minutes and

548 resuspended in $2 \mathrm{~mL}$ of SM-plus buffer. One-third volume chloroform was mixed by inversion into the

549 phage precipitates and centrifuged at $16,300 \times g$ to separate out residual PEG 8000 into the organic

550 phase. Phages in the aqueous phase were further purified using a cesium chloride gradient as

551 described previously (11). The final titer was confirmed by plaque assay. Crude phage lysates were

552 used for all phage susceptibility and adsorption assays, while cesium chloride gradient purified phages

553 were used for phage genomic DNA isolation and transmission electron microscopy.

555 Transmission electron microscopy. $8 \mu \mathrm{l}$ of $1 \times 10^{10} \mathrm{pfu} / \mathrm{mL}$ of phages was applied to a copper mesh 556 grid coated with formvar and carbon (Electron Microscopy Sciences) for 2 minutes and then gently 557 blotted off with a piece of Whatman filter paper. The grids were rinsed by transferring between two 558 drops of MilliQ water, blotting with Whatman filter paper between each transfer. Finally, the grids were 559 stained using two drops of a $0.75 \%$ uranyl formate solution (a quick rinse with MilliQ water following the 560 first drop followed by an additional 20 seconds of staining). After rinsing and blotting, the grids were 561 allowed to dry for at least 10 minutes. Samples were imaged on a FEI Tecnai G2 Biotwin TEM at 80kV 562 with an AMT side-mount digital camera. 
564 Whole-genome sequence analysis of phages and phage-resistant bacteria. Phage DNA was

565 isolated by incubating phages with $50 \mu \mathrm{g} / \mathrm{mL}$ proteinase $\mathrm{K}$ and $0.5 \%$ sodium dodecyl sulfate at $56^{\circ} \mathrm{C}$ for

5661 hour followed by extraction with an equal volume of phenol/chloroform. The aqueous phase was

567 extracted a second time with an equal volume of chloroform and the DNA was precipitated using

568 isopropanol. Bacterial DNA was isolated using a ZymoBIOMICS DNA miniprep kit (Zymo Research),

569 following the manufacturers protocol. Phage and bacterial DNA samples were sequenced at the

570 Microbial Genome Sequencing Center, University of Pittsburgh, using an Illumina NextSeq 550 platform

571 and paired end chemistry $(2 \times 150 \mathrm{bp})$. Paired-end reads were trimmed and assembled into contigs

572 using CLC genomics workbench (Qiagen). Open reading frames (ORFs) were detected and annotated

573 using rapid annotation subsystem technology (RAST) and the Phage Galaxy structural annotation

574 (version 2020.1) and functional workflows (version 2020.3) $(68,69)$. Trimmed bacterial genomic reads

575 for $E$. faecium Com12, 1,141,733, and phage resistant derivatives were mapped to reference genomes

576 (GCF_000157635.1 (Com12); GCA_000157575.1 (1,141,733)), downloaded from the National Center

577 for Biotechnology Information (NCBI) website. To identify mutations conferring phage resistance the

578 basic variant detection tool from CLC genomics workbench was used to identify polymorphisms

579 (similarity fraction $=0.5$ and length fraction $=0.8$ ).

PCR screen for phage lysogeny. PCR primers to screen for phage 9181,9183 , and 9184 lysogeny were designed to target the phage lysin (phage 9181 and 9184) or integrase (phage 9183) genes (Table S4). PCR was performed using GoTaq Green master mix (Promega), per the manufacturer's

584 instructions. Bands were visualized from PCR reactions following electrophoresis of $10 \mu \mathrm{L}$ of each

585 reaction loaded onto 1\% (phage 9184) or 1.5\% (phage 9181 and 9183) agarose gels embedded with

586 ethidium bromide. Predicted PCR product sizes were as follows: phage 9181 lysin gene

587 (phi9181_ORF001), 432bp; phage 9183 integrase gene (phi9183_ORF077), 514bp; phage 9184 lysin 588 gene (phi9184_ORF022), 801bp. 
591 Enterococcal phage orthology analysis. Enterococcal phage orthology was performed according to

592 a method described by Bolocan et al. (16). Briefly, publicly available enterococcal genomes were

593 downloaded from the Millard Lab phage genome database (http://millardlab.org/bioinformatics/). As of

594 May 15, 2020, there were 99 complete enterococcal phage genomes. Open reading frames for each

595 enterococcal phage genome were called using Prodigal and bacteriophage protein Orthologous Groups

596 were identified by OrthoMCL $(20,70)$. The resulting OrthoMCL matrix was used to generate an

597 orthology tree using the ggplot2 and ggdendro packages in R. Nearest neighbor phages to phages

5989181,9183 , and 9184 from the OrthoMCL analysis were compared using the genome alignment

599 feature of ViP Tree using normalized tBLASTx scores between viral genomes to calculate genomic

600 distance for phylogenetic proteomic tree analysis (71).

Routine molecular techniques, DNA sequencing, and complementation. Confirmation PCRs were

performed using GoTaq Green master mix (Promega), per the manufacturer's instructions. Q5 DNA polymerase master mix (New England Biolabs) was used for PCR reactions intended for cloning, per the manufacturer's instructions. Plasmid DNA was purified using a QIAprep Miniprep kit (Qiagen) or a ZymoPURE II Plasmid Midiprep kit (Zymo Research). Restriction enzymes and T4 ligase were purchased from New England Biolabs. Sanger DNA sequencing was performed by Quintara Biosciences (San Francisco, CA). A complete list of primers can be found in Table S4. Complementation was performed using plasmid $\mathrm{pLZ12A}$, a derivative of $\mathrm{pLZ12}$ (72) carrying the bacA 610 promoter upstream of the multiple cloning site (9). wze, epaX, dltA, and efsg_rs08090 were cloned into $611 \mathrm{pLZ12A}$ as BamHI and EcoRI fragments. epaR and efsg_rs08120 were cloned into pLZ12A as BamHI 612 and Pstl fragments. Plasmids were transformed into E. faecium using a previously described glycine613 sucrose method $(73,74)$. Briefly, $1 \mathrm{ml}$ of overnight culture was inoculated into $50 \mathrm{ml}$ of $\mathrm{BHI}$

614 supplemented with $2 \%$ glycine and $0.5 \mathrm{M}$ sucrose and grown overnight at $37^{\circ} \mathrm{C}$ with rotation (250 rpm).

615 The following day the cells were pelleted at $7200 \times g$ and re-suspended in an equal volume of pre-

616 warmed $\mathrm{BHI}$ supplemented with $2 \%$ glycine and $0.5 \mathrm{M}$ sucrose and incubated for $1 \mathrm{~h}$ at $37^{\circ} \mathrm{C}$ statically.

617 The cells were pelleted at $7200 \times g$ and washed three times in ice cold electroporation buffer (0.5 M 
618 sucrose and $10 \%$ glycerol). 1-2 $\mu \mathrm{g}$ of plasmid DNA was electroporated into E. faecium using a Gene

619 Pulser (Bio-Rad) with a $0.2 \mathrm{~mm}$ cuvette at $1.7 \mathrm{kV}, 200 \Omega$ and $25 \mu \mathrm{F}$.

621 Phage susceptibility assay. Overnight bacterial cultures were pelleted, re-suspended in SM-plus

622 buffer, and normalized to $\mathrm{OD}_{600}$ of 1.0. 10-fold serial dilutions of bacteria were spotted on THB agar

623 embedded with phage or THB agar alone, supplemented with $10 \mathrm{mM} \mathrm{MgSO}_{4}$. Phages were embedded

624 at the following concentrations within THB agar: phage $9181\left(10^{8} \mathrm{PFU} / \mathrm{ml}\right)$, phage $9183\left(10^{7} \mathrm{PFU} / \mathrm{ml}\right)$,

625 and phage $9184\left(10^{7} \mathrm{PFU} / \mathrm{ml}\right)$. Plates were incubated overnight at $37^{\circ} \mathrm{C}$ and viable CFU was

626 determined by colony counting.

Isolation of phage-resistant $\boldsymbol{E}$. faecium strains. $130 \mu \mathrm{l}$ of a 1:10 dilution of $E$. faecium grown $\mathrm{O} / \mathrm{N}$

was mixed with $10 \mu \mathrm{l}$ of 10 -fold serially diluted phages and added to $5 \mathrm{ml}$ of pre-warmed THB top agar

$(0.35 \% \mathrm{wt} / \mathrm{vol})$. Phage-bacterium mixtures were poured onto the surface of THB agar plates $(1.5 \%$

$\mathrm{wt} / \mathrm{vol})$. The plates were incubated at $37^{\circ} \mathrm{C}$ until phage-resistant colonies appeared in the zones of clearing. The presumptive resistant colonies were passaged four times by streaking single colonies onto THB agar.

Determination of phage host range. The host range of phages 9181,9183 , and 9184 were determined using a panel of laboratory and contemporary clinical E. faecium and E. faecalis isolates (Table S4). Overnight bacterial cultures were suspended in SM-plus buffer to an $\mathrm{OD}_{600}$ of 1.0 and 10 fold serially diluted and spotted on to THB agar containing phages. Plates were incubated $\mathrm{O} / \mathrm{N}$ at $37^{\circ} \mathrm{C}$ and viable CFU was determined. Strains that exhibited greater than 4-log killing in the presence of phage were termed phage susceptible, while those that grew beyond this threshold were considered

641 phage resistant.

Efficiency of plating. Bacterial strains of interest were selected from a single colony to inoculate $3 \mathrm{~mL}$ $644 \mathrm{THB}$ and incubated $\mathrm{O} / \mathrm{N}$ at $37^{\circ} \mathrm{C}$ with agitation. Bacteria from $\mathrm{O} / \mathrm{N}$ cultures were 1:10 diluted in SM-plus 
645 buffer and $130 \mu \mathrm{L}$ was mixed gently with $10 \mu \mathrm{L}$ of phage 9181 and phage 9184 serially $1: 10$ diluted in

646 SM-plus buffer using starting titers of $5 \times 10^{6}$ pfu and $1 \times 10^{7} \mathrm{pfu}$, respectively. This phage and

647 bacterial mixture was incubated at room temperature for 15 minutes to enable phage attachment before

$6485 \mathrm{~mL}$ of pre-warmed THB soft agar ( $0.35 \% \mathrm{wt} / \mathrm{vol})$ supplemented with $10 \mathrm{mM}$ magnesium sulfate was

649 mixed in and spread over the surface of THB agar (1.5\% wt/vol) supplemented with $10 \mathrm{mM}$ magnesium

650 sulfate. The soft agar was allowed to solidify and then incubated $\mathrm{O} / \mathrm{N}$ at $37^{\circ} \mathrm{C}$ with the petri dish upright

651 to prevent dislodgement of the soft agar. Phage plaques were enumerated following O/N incubation.

652 Given our difficulties forming an evenly spread plaque layer of phage 9184 on E. faecium U37 (75), 6

$653 \mu \mathrm{L}$ of 10 -fold serial dilutions of phage 9184 were spotted onto bacterial lawns of E. faecium U37 or

$6541,141,733$ embedded in THB soft agar (0.35 wt/vol) supplemented with $10 \mathrm{mM}$ magnesium sulfate

655 containing either. Following drying of spots, plates were incubated upright $\mathrm{O} / \mathrm{N}$ at $37^{\circ} \mathrm{C}$. Plaques were

656 enumerated following $\mathrm{O} / \mathrm{N}$ incubation.

Western blot analysis for SagA from bacterial supernatants and pellets. Western blot was

performed as described previously (22). Briefly, bacteria were grown to exponential phase $\left(\mathrm{OD}_{600} \sim 0.8\right)$

in $\mathrm{BHI}$. $1 \mathrm{~mL}$ exponential phase culture samples were centrifuged at $\geq 18,000 \times \mathrm{g}$ and the supernatants

were transferred to a new microcentrifuge tube for preparation. Supernatants were prepared as follows:

$10 \%$ trichloroacetic acid (final; vol/vol) was added and tubes placed at $-20^{\circ} \mathrm{C}$ for 15 minutes for protein

precipitation. Tubes were then spun at max speed for 15 minutes, supernatant discarded, and the

protein pellet was washed twice with $500 \mu \mathrm{L}$ cold acetone. Tubes were transferred to a $95^{\circ} \mathrm{C}$ heat block

with caps open to evaporate acetone and dry protein pellets. $60 \mu \mathrm{L} 4 \%$ sodium dodecyl sulfate (SDS)

buffer (4\% SDS, 50 mM Bis-Tris pH 7.5, 150 mM sodium chloride, 1 X Laemmli Buffer, 2.5\% $\beta$ -

mercaptoethanol) was added to the protein pellets, which were sonicated for 5 minutes to solubilize.

668 The samples were then placed at $95^{\circ} \mathrm{C}$ for 5 minutes to denature proteins. Cell pellets were prepared

669 as follows: $1 \mathrm{~mL}$ cell pellets were resuspended with $1 \mathrm{~mL}$ phosphate buffered saline, transferred to 2

$670 \mathrm{~mL}$ cryovials, and centrifuged at $5000 \times \mathrm{g}$ for 5 minutes to wash. After discarding supernatant, $50 \mu \mathrm{L}$

$6710.1 \mathrm{~mm}$ beads were added followed by $250 \mu \mathrm{L} 4 \%$ SDS buffer (see above). Cryovial tubes were placed 
672 in a FastPrep FP120 cell disruptor at max speed for 20 seconds on and 10 seconds off, and this

673 process was repeated twice more. Tubes were then centrifuged at $5000 \mathrm{xg}$ for one minute and then

674 placed at $95^{\circ} \mathrm{C}$ for 10 minutes to remove bubbles \& denature proteins. $15 \mu \mathrm{L}$ of $60 \mu \mathrm{L}$ supernatant or

675 cell pellet sample was loaded for SDS-PAGE. Proteins were separated by SDS-PAGE on 4-20\%

676 Criterion TGX precast gels (Bio-Rad), then transferred to nitrocellulose membrane $(0.2 \mathrm{mM}$, BioTrace

677 NT Nitrocellulose Transfer Membranes, Pall Laboratory). For SagA blots, polyclonal SagA serum and

678 HRP conjugated anti-Rabbit IgG (GE Healthcare, NA 934V) served as primary and secondary

679 antibodies, respectively. Polyclonal SagA primary antibodies and secondary antibody were used at a

680 dilution of $1: 25000$ and 1:10000 (supernatants) or 1:10000 and 1:5000 (cell pellets), respectively.

681 Membranes were blocked for one hour in TBS-T (Tris-buffered saline, $0.1 \%$ Tween 20) containing 5\%

682 non-fat milk, incubated with blocking buffer containing primary antibody for one hour, washed five times

683 with TBS-T, incubated with blocking buffer containing secondary antibody, and washed four times with

684 TBS-T. Protein detection was performed with ECL detection reagent (GE Healthcare) on a Bio-Rad

685 ChemiDoc MP Imaging System.

687 Bacterial growth curves. $250 \mathrm{~mL} \mathrm{BHI}$ was inoculated with $2.5 \mathrm{~mL}$ (1:100) overnight cultures and 688 incubated at $37^{\circ} \mathrm{C}$ with agitation until $\mathrm{OD}_{600} \sim 0.8$.

Phage adsorption assay. This assay was performed as described previously $(10,11)$. O/N bacterial

691 cultures were pelleted at $3220 \times \mathrm{g}$ for $10 \mathrm{~min}$ and resuspended to $10^{8} \mathrm{CFU} / \mathrm{mL}$ in SM-plus buffer. Phage 692 adsorption was determined by mixing $5 \times 10^{6} \mathrm{pfu}$ of phage and to $5 \times 10^{7} \mathrm{cfu}$ of the appropriate 693 bacterial strain in $500 \mu \mathrm{L}$ and incubating statically at room temperature for $10 \mathrm{~min}$. The bacteria-phage 694 suspensions were centrifuged at $24,000 \times g$ for $1 \mathrm{~min}$, the supernatant was collected, and remaining 695 phages enumerated by a plaque assay. SM-plus buffer with phage only (no bacteria) served as a 696 control. Percent adsorption was determined as follows: [(PFU $\left.\left.{ }_{\text {control }}-\mathrm{PFU}_{\text {test supernatant }}\right) / \mathrm{PFU}_{\text {control }}\right] \times 100$.

697 The fold change was calculated by dividing the percent adsorption of phage resistant mutants by those 698 of parental strain. 
700 Antibiotic MIC assay. Antibiotic MIC was determined for each strain using Etest strips (bioMérieux).

701 Single colonies were grown $\mathrm{O} / \mathrm{N}$ in $3 \mathrm{~mL}$ of $\mathrm{MHB}$ broth at $37^{\circ} \mathrm{C}$ with rotation (250 rpm). The following 702 day overnight cultures were diluted to McFarland 0.5 in MHB broth and $100 \mu \mathrm{L}$ of the cell suspension 703 was spread over the surface of MHB agar plates. One Etest strip was placed on the surface of the agar 704 using sterile forceps. The plates were incubated for 18 hours at $37^{\circ} \mathrm{C}$. The MIC was determined to be 705 the number closest to the zone of inhibition. The mean and standard deviation of the MIC from three 706 independent experiments is reported for each strain.

Phage-antibiotic synergy assay. O/N cultures of E. faecium Com12 and E. faecium 1,141,733 were normalized to $10^{8} \mathrm{CFU} / \mathrm{mL}$. $100 \mu \mathrm{l}\left(10^{7} \mathrm{CFU} / \mathrm{mL}\right)$ of bacteria was added into a sterile 96-well plate in triplicate. Antibiotics were diluted 1:100 into desired wells to achieve the appropriate final concentration. Phages were added to desired wells at $10^{6} \mathrm{PFU} / \mathrm{mL}$, achieving a multiplicity of infection of 0.1 . The 96 well plate was loaded on to BioTek Synergy Plate reader pre-warmed to $37^{\circ} \mathrm{C}$, and agitated continuously for $18 \mathrm{~h}$, allowing for $\mathrm{OD}_{600}$ reading every 30 minutes.

Data availability. The Illumina reads for phage 9181,9183 , and 9184 and phage-resistant E. faecium 716 mutants have been deposited in the European Nucleotide Archive under the accession number PRJEB39873. Assembled phage genomes were submitted to Genbank and were assigned the 718 following accession numbers: MT939240 (phage 9181), MT939241 (phage 9183), and MT939242 719 (phage 9184).

\section{Acknowledgements.}

This work was supported by National Institutes of Health grants R01Al141479 (B.A.D.), R01GM103593 (H.C.H), R01CA245292 (H.C.H.), T32AI070084 (J.E.), and T32AR007534 (M.R.M). J.E. acknowledges support from The Rockefeller University Graduate Program and H.C.H. acknowledges support from a 
726 School of Medicine Electron Microscopy Center for preparing and visualizing electron micrographs of 727 phages. We thank the staff at the Microbial Genome Sequencing Center (MiGS) at the University of 728 Pittsburgh for assistance with bacterial and phage whole genome DNA sequencing.

\section{References.}

731 1. Arias CA, Murray BE. 2012. The rise of the Enterococcus: beyond vancomycin resistance. Nat 732 Rev Microbiol 10:266-78. doi:10.1038/nrmicro2761.

$7332 . \quad$ Kristich CJ, Rice LB, Arias CA. 2014. Enterococcal infection-treatment and antibiotic 734 resistance, p 1-62. In Gilmore MS, Clewell DB, Ike Y, Shakar N (ed), Enterococci : from 735 commensals to leading causes of drug resistant infection [Internet]. Massachusetts Eye and Ear 736 Infirmary, Boston, MA.

737 3. Beganovic M, Luther MK, Rice LB, Arias CA, Rybak MJ, LaPlante KL. 2018. A review of combination antimicrobial therapy for Enterococcus faecalis bloodstream infections and infective

4. Rybak MJ, McGrath BJ. 1996. Combination antimicrobial therapy for bacterial infections. Guidelines for the clinician. Drugs 52:390-405. doi:10.2165/00003495-199652030-00005.

742 5. Fish R, Kutter E, Bryan D, Wheat G, Kuhl S. 2018. Resolving digital staphylococcal osteomyelitis using bacteriophage-a case report. Antibiotics (Basel) 7:87.

6. Cano EJ, Caflisch KM, Bollyky PL, Van Belleghem JD, Patel R, Fackler J, Brownstein MJ, Horne B, Biswas B, Henry M, Malagon F, Lewallen DG, Suh GA. 2020. Phage therapy for limbthreatening prosthetic knee Klebsiella pneumoniae infection: case report and in vitro characterization of anti-biofilm activity. Clin Infect Dis doi:10.1093/cid/ciaa705. doi:10.1093/cid/ciaa705. 
750 7. Schooley RT, Biswas B, Gill JJ, Hernandez-Morales A, Lancaster J, Lessor L, Barr JJ, Reed SL,

8. Chan BK, Turner PE, Kim S, Mojibian HR, Elefteriades JA, Narayan D. 2018. Phage treatment of an aortic graft infected with Pseudomonas aeruginosa. Evol Med Public Health 2018:60-66.

9. Chatterjee A, Johnson CN, Luong P, Hullahalli K, McBride SW, Schubert AM, Palmer KL,

Carlson PE, Jr., Duerkop BA. 2019. Bacteriophage resistance alters antibiotic-mediated

10. Chatterjee A, Willett JLE, Nguyen UT, Monogue B, Palmer KL, Dunny GM, Duerkop BA. 2020.

Parallel genomics uncover novel enterococcal-bacteriophage interactions. mBio 11:e03120-19. doi:10.1128/mBio.03120-19.

11. Duerkop BA, Huo W, Bhardwaj P, Palmer KL, Hooper LV. 2016. Molecular basis for lytic bacteriophage resistance in enterococci. mBio 7:e01304-16. doi:10.1128/mBio.01304-16.

12. Wandro S, Oliver A, Gallagher T, Weihe C, England W, Martiny JBH, Whiteson K. 2018.

13. Lossouarn J, Briet A, Moncaut E, Furlan S, Bouteau A, Son O, Leroy M, DuBow MS, Lecointe F, bacteriophage. Viruses 11:48. doi:10.3390/v11010048. 
774 14. Ho K, Huo W, Pas S, Dao R, Palmer KL. 2018. Loss-of-function mutations in epaR confer resistance to phiNPV1 Infection in Enterococcus faecalis OG1RF. Antimicrob Agents Chemother 62:e00758-18. doi:10.1128/AAC.00758-18.

15. Duerkop BA, Palmer KL, Horsburgh MJ. 2014. Enterococcal bacteriophages and genome defense, p 1-44. In Gilmore MS, Clewell DB, Ike Y, Shankar N (ed), Enterococci: from

16. Bolocan AS, Upadrasta A, Bettio PHA, Clooney AG, Draper LA, Ross RP, Hill C. 2019. Evaluation of phage therapy in the context of Enterococcus faecalis and its associated diseases. Viruses 11:366. doi:10.3390/v11040366.

17. Palmer KL, Godfrey P, Griggs A, Kos VN, Zucker J, Desjardins C, Cerqueira G, Gevers D, Walker S, Wortman J, Feldgarden M, Haas B, Birren B, Gilmore MS. 2012. Comparative genomics of enterococci: variation in Enterococcus faecalis, clade structure in E. faecium, and defining characteristics of E. gallinarum and E. casseliflavus. mBio 3:e00318-11.

18. de Been M, van Schaik W, Cheng L, Corander J, Willems RJ. 2013. Recent recombination events in the core genome are associated with adaptive evolution in Enterococcus faecium. Genome Biol Evol 5:1524-35. doi:10.1093/gbe/evt111.

19. Ackermann HW. 2007. 5500 Phages examined in the electron microscope. Arch Virol 152:22743. doi:10.1007/s00705-006-0849-1.

20. Li L, Stoeckert CJ, Jr., Roos DS. 2003. OrthoMCL: identification of ortholog groups for eukaryotic genomes. Genome Res 13:2178-89. doi:10.1101/gr.1224503. 
796 21. Holtzman T, Globus R, Molshanski-Mor S, Ben-Shem A, Yosef I, Qimron U. 2020. A continuous evolution system for contracting the host range of bacteriophage T7. Sci Rep 10:307.

22. Kim B, Wang YC, Hespen CW, Espinosa J, Salje J, Rangan KJ, Oren DA, Kang JY, Pedicord doi:10.1038/s41598-019-57221-0.

\section{3}

23. Ittisoponpisan S, Islam SA, Khanna T, Alhuzimi E, David A, Sternberg MJE. 2019. Can predicted protein 3D structures provide reliable insights into whether missense variants are

24. Rangan KJ, Pedicord VA, Wang YC, Kim B, Lu Y, Shaham S, Mucida D, Hang HC. 2016. A secreted bacterial peptidoglycan hydrolase enhances tolerance to enteric pathogens. Science

25. Guerardel Y, Sadovskaya I, Maes E, Furlan S, Chapot-Chartier MP, Mesnage S, Rigottier-Gois 353:1434-1437. doi:10.1126/science.aaf3552.

814 26. Kortright KE, Chan BK, Koff JL, Turner PE. 2019. Phage therapy: a renewed approach to L, Serror P. 2020. Complete structure of the enterococcal polysaccharide antigen (EPA) of vancomycin-resistant Enterococcus faecalis V583 Reveals that EPA decorations are teichoic acids covalently linked to a rhamnopolysaccharide backbone. mBio 11:e00277-20. doi:10.1128/mBio.00277-20. combat antibiotic-resistant bacteria. Cell Host Microbe 25:219-232. doi:10.1016/j.chom.2019.01.014.

27. Mangalea MR, Duerkop BA. 2020. Fitness trade-offs resulting from bacteriophage resistance potentiate synergistic antibacterial strategies. Infect Immun 88:e00926-19. doi:10.1128/IAI.00926-19. 
820 28. Morrisette T, Lev KL, Kebriaei R, Abdul-Mutakabbir J, Stamper KC, Morales S, Lehman SM, Canfield GS, Duerkop BA, Arias CA, Rybak MJ. 2020. Bacteriophage-antibiotic combinations for

29. Al-Zubidi M, Widziolek M, Court EK, Gains AF, Smith RE, Ansbro K, Alrafaie A, Evans C, Enterococcus faecium with varying bacteriophage and daptomycin susceptibilities. Antimicrob Agents Chemother 64:e00993-20. doi:10.1128/AAC.00993-20.

828

Murdoch C, Mesnage S, Douglas CWI, Rawlinson A, Stafford GP. 2019. Identification of Novel Bacteriophages with Therapeutic Potential That Target Enterococcus faecalis. Infect Immun 87:e00512-19. doi:10.1128/iai.00512-19.

30. Smith RE, Salamaga B, Szkuta P, Hajdamowicz N, Prajsnar TK, Bulmer GS, Fontaine T, Kolodziejczyk J, Herry JM, Hounslow AM, Williamson MP, Serror P, Mesnage S. 2019. Decoration of the enterococcal polysaccharide antigen EPA is essential for virulence, cell surface charge and interaction with effectors of the innate immune system. PLoS Pathog 15:e1007730. doi:10.1371/journal.ppat.1007730.

31. Rodriguez C, Van der Meulen R, Vaningelgem F, Font de Valdez G, Raya R, De Vuyst L, Mozzi F. 2008. Sensitivity of capsular-producing Streptococcus thermophilus strains to bacteriophage adsorption. Lett Appl Microbiol 46:462-8. doi:10.1111/j.1472-765X.2008.02341.x.

32. Rice LB, Lakticová V, Helfand MS, Hutton-Thomas R. 2004. In vitro antienterococcal activity explains associations between exposures to antimicrobial agents and risk of colonization by multiresistant enterococci. J Infect Dis 190:2162-6. doi:10.1086/425580.

33. Ubeda C, Taur Y, Jenq RR, Equinda MJ, Son T, Samstein M, Viale A, Socci ND, van den Brink MR, Kamboj M, Pamer EG. 2010. Vancomycin-resistant Enterococcus domination of intestinal microbiota is enabled by antibiotic treatment in mice and precedes bloodstream invasion in humans. J Clin Invest 120:4332-41. doi:10.1172/JCI43918. 
843 34. Brandl K, Plitas G, Mihu CN, Ubeda C, Jia T, Fleisher M, Schnabl B, DeMatteo RP, Pamer EG. 2008. Vancomycin-resistant enterococci exploit antibiotic-induced innate immune deficits.

846

847

848

849

850

851

852

853

854

855

856

857

858

859

860

861

862

863

864

865

866

867 Nature 455:804-7. doi:10.1038/nature07250.

35. Donskey CJ, Chowdhry TK, Hecker MT, Hoyen CK, Hanrahan JA, Hujer AM, Hutton-Thomas RA, Whalen CC, Bonomo RA, Rice LB. 2000. Effect of antibiotic therapy on the density of vancomycin-resistant enterococci in the stool of colonized patients. N Engl J Med 343:1925-32. doi:10.1056/NEJM200012283432604.

36. Hendrickx AP, Top J, Bayjanov JR, Kemperman H, Rogers MR, Paganelli FL, Bonten MJ, Willems RJ. 2015. Antibiotic-driven dysbiosis mediates intraluminal agglutination and alternative segregation of Enterococcus faecium from the intestinal epithelium. mBio 6:e01346-15. doi:10.1128/mBio.01346-15.

37. Duan Y, Llorente C, Lang S, Brandl K, Chu H, Jiang L, White RC, Clarke TH, Nguyen K, Torralba M, Shao Y, Liu J, Hernandez-Morales A, Lessor L, Rahman IR, Miyamoto Y, Ly M, Gao B, Sun W, Kiesel R, Hutmacher F, Lee S, Ventura-Cots M, Bosques-Padilla F, Verna EC, Abraldes JG, Brown RS, Jr., Vargas V, Altamirano J, Caballeria J, Shawcross DL, Ho SB, Louvet A, Lucey MR, Mathurin P, Garcia-Tsao G, Bataller R, Tu XM, Eckmann L, van der Donk WA, Young R, Lawley TD, Starkel P, Pride D, Fouts DE, Schnabl B. 2019. Bacteriophage targeting of gut bacterium attenuates alcoholic liver disease. Nature 575:505-511. doi:10.1038/s41586-019-1742-x.

38. Stein-Thoeringer CK, Nichols KB, Lazrak A, Docampo MD, Slingerland AE, Slingerland JB, Clurman AG, Armijo G, Gomes ALC, Shono Y, Staffas A, Burgos da Silva M, Devlin SM, Markey KA, Bajic D, Pinedo R, Tsakmaklis A, Littmann ER, Pastore A, Taur Y, Monette S, Arcila ME, Pickard AJ, Maloy M, Wright RJ, Amoretti LA, Fontana E, Pham D, Jamal MA, Weber D, Sung AD, Hashimoto D, Scheid C, Xavier JB, Messina JA, Romero K, Lew M, Bush A, Bohannon L, Hayasaka K, Hasegawa Y, Vehreschild M, Cross JR, Ponce DM, Perales MA, 

expansion to promote graft-versus-host disease. Science 366:1143-1149.

39. Baddour LM, Wilson WR, Bayer AS, Fowler VG, Jr., Tleyjeh IM, Rybak MJ, Barsic B, Lockhart PB, Gewitz MH, Levison ME, Bolger AF, Steckelberg JM, Baltimore RS, Fink AM, O'Gara P, Taubert KA, American Heart Association Committee on Rheumatic Fever E, Kawasaki Disease of the Council on Cardiovascular Disease in the Young CoCCCoCS, Anesthesia, Stroke C. 2015. Infective endocarditis in adults: diagnosis, antimicrobial therapy, and management of

40. Lorenzo MP, Kidd JM, Jenkins SG, Nicolau DP, Housman ST. 2019. In vitro activity of ampicillin and ceftriaxone against ampicillin-susceptible Enterococcus faecium. J Antimicrob Chemother

41. Djoric D, Little JL, Kristich CJ. 2020. Multiple low-reactivity class B penicillin-binding proteins are required for cephalosporin resistance in enterococci. Antimicrob Agents Chemother 64:e02273-

42. Arbeloa A, Segal H, Hugonnet JE, Josseaume N, Dubost L, Brouard JP, Gutmann L, Mengin19. doi:10.1128/AAC.02273-19.

43. Rice LB, Carias LL, Rudin S, Hutton R, Marshall S, Hassan M, Josseaume N, Dubost L, Marie Lecreulx D, Arthur M. 2004. Role of class A penicillin-binding proteins in PBP5-mediated betaresistance in Enterococcus faecium. J Bacteriol 191:3649-56. doi:10.1128/JB.01834-08. 
44. Sifaoui F, Arthur M, Rice L, Gutmann L. 2001. Role of penicillin-binding protein 5 in expression of ampicillin resistance and peptidoglycan structure in Enterococcus faecium. Antimicrob Agents

45. Djoric D, Kristich CJ. 2017. Extracellular SalB contributes to intrinsic cephalosporin resistance and cell envelope integrity in Enterococcus faecalis. J Bacteriol 199:e00392-17.

46. Singh KV, Murray BE. 2019. Loss of a major enterococcal polysaccharide antigen (Epa) by Enterococcus faecalis is associated with increased resistance to ceftriaxone and carbapenems.

47. Dale JL, Cagnazzo J, Phan CQ, Barnes AM, Dunny GM. 2015. Multiple roles for Enterococcus Antimicrob Agents Chemother 63:e00481-19. doi:10.1128/aac.00481-19.

48. Gaupp R, Lei S, Reed JM, Peisker H, Boyle-Vavra S, Bayer AS, Bischoff M, Herrmann M, faecalis glycosyltransferases in biofilm-associated antibiotic resistance, cell envelope integrity, and conjugative transfer. Antimicrob Agents Chemother 59:4094-105. doi:10.1128/AAC.00344-

49. Mechler L, Bonetti EJ, Reichert S, Flotenmeyer M, Schrenzel J, Bertram R, Francois P, Gotz F. 2016. Daptomycin tolerance in the Staphylococcus aureus pitA6 mutant is due to upregulation

50. Bertsche U, Weidenmaier C, Kuehner D, Yang SJ, Baur S, Wanner S, Francois P, Schrenzel J, 
aureus strain with increased cell wall teichoic acid production and D-alanylation. Antimicrob Agents Chemother 55:3922-8. doi:10.1128/AAC.01226-10.

51. Mello SS, Van Tyne D, Lebreton F, Silva SQ, Nogueira MCL, Gilmore MS, Camargo I. 2020. A mutation in the glycosyltransferase gene lafB causes daptomycin hypersusceptibility in

52. Sieradzki K, Tomasz A. 1997. Inhibition of cell wall turnover and autolysis by vancomycin in a highly vancomycin-resistant mutant of Staphylococcus aureus. Journal of Bacteriology

53. Xu Y, Singh KV, Qin X, Murray BE, Weinstock GM. 2000. Analysis of a gene cluster of Enterococcus faecalis involved in polysaccharide biosynthesis. Infect Immun 68:815-23.

54. Rigottier-Gois L, Madec C, Navickas A, Matos RC, Akary-Lepage E, Mistou MY, Serror P. 2015. The surface rhamnopolysaccharide epa of Enterococcus faecalis is a key determinant of intestinal colonization. J Infect Dis 211:62-71. doi:10.1093/infdis/jiu402.

55. Mohamed JA, Huang W, Nallapareddy SR, Teng F, Murray BE. 2004. Influence of origin of isolates, especially endocarditis isolates, and various genes on biofilm formation by

56. Ramos Y, Rocha J, Hael AL, van Gestel J, Vlamakis H, Cywes-Bentley C, Cubillos-Ruiz JR, 
appears essential for E. faecium growth. Infect Immun 71:5033-41. doi:10.1128/iai.71.9.5033-

939

940

941

942

943

944

945

946

947

948

949

950

951

952

953

954

955

956

957

958

959

5041.2003 .

58. Breton YL, Mazé A, Hartke A, Lemarinier S, Auffray Y, Rincé A. 2002. Isolation and characterization of bile salts-sensitive mutants of Enterococcus faecalis. Current Microbiology 45:0434-0439. doi:10.1007/s00284-002-3714-3.

59. Rincé A, Le Breton Y, Verneuil N, Giard J-C, Hartke A, Auffray Y. 2003. Physiological and molecular aspects of bile salt response in Enterococcus faecalis. International Journal of Food Microbiology 88:207-213. doi:10.1016/s0168-1605(03)00182-x.

60. Mohamed JA, Teng F, Nallapareddy SR, Murray BE. 2006. Pleiotrophic effects of 2 Enterococcus faecalis sagA-like genes, salA and salB, which encode proteins that are antigenic during human infection, on biofilm formation and binding to collagen type i and fibronectin. $J$ Infect Dis 193:231-40. doi:10.1086/498871.

61. Shankar J, Walker RG, Wilkinson MC, Ward D, Horsburgh MJ. 2012. SalB inactivation modulates culture supernatant exoproteins and affects autolysis and viability in Enterococcus faecalis OG1RF. J Bacteriol 194:3569-78. doi:10.1128/JB.00376-12.

62. Perez-Cheeks BA, Lee C, Hayama R, Marians KJ. 2012. A role for topoisomerase III in Escherichia coli chromosome segregation. Mol Microbiol 86:1007-22. doi:10.1111/mmi.12039.

63. Llobet E, Tomas JM, Bengoechea JA. 2008. Capsule polysaccharide is a bacterial decoy for antimicrobial peptides. Microbiology (Reading) 154:3877-3886. doi:10.1099/mic.0.2008/022301-

0.

64. Zavascki AP, Goldani LZ, Li J, Nation RL. 2007. Polymyxin B for the treatment of multidrugresistant pathogens: a critical review. Journal of Antimicrobial Chemotherapy 60:1206-1215. doi:10.1093/jac/dkm357. 
65. Dunne M, Rupf B, Tala M, Qabrati X, Ernst P, Shen Y, Sumrall E, Heeb L, Pluckthun A, Loessner MJ, Kilcher S. 2019. Reprogramming bacteriophage host range through structureguided design of chimeric receptor binding proteins. Cell Rep 29:1336-1350 e4.

66. Burrowes BH, Molineux IJ, Fralick JA. 2019. Directed in vitro evolution of therapeutic bacteriophages: the appelmans protocol. Viruses 11:241. doi:10.3390/v11030241.

67. Yehl K, Lemire S, Yang AC, Ando H, Mimee M, Torres MT, de la Fuente-Nunez C, Lu TK. 2019.

68. Aziz RK, Bartels D, Best AA, DeJongh M, Disz T, Edwards RA, Formsma K, Gerdes S, Glass mutagenesis. Cell 179:459-469 e9. doi:10.1016/j.cell.2019.09.015. Zagnitko O. 2008. The RAST Server: rapid annotations using subsystems technology. BMC Genomics 9:75. doi:10.1186/1471-2164-9-75.

69. Mijalis E, Rasche H. 2013-2017. CPT galaxy tools. https://github.com/tamu-cpt/galaxy-tools/

979 71. Nishimura Y, Yoshida T, Kuronishi M, Uehara H, Ogata H, Goto S. 2017. ViPTree: the viral Accessed 1 May 2020.

70. Hyatt D, Chen GL, Locascio PF, Land ML, Larimer FW, Hauser LJ. 2010. Prodigal: prokaryotic gene recognition and translation initiation site identification. BMC Bioinformatics 11:119. doi:10.1186/1471-2105-11-119.

proteomic tree server. Bioinformatics 33:2379-2380. doi:10.1093/bioinformatics/btx157. 
981 72. Perez-Casal J, Caparon MG, Scott JR. 1991. Mry, a trans-acting positive regulator of the M protein gene of Streptococcus pyogenes with similarity to the receptor proteins of two-

73. Shepard BD, Gilmore MS. 1995. Electroporation and efficient transformation of Enterococcus faecalis grown in high concentrations of glycine. Methods Mol Biol 47:217-26. doi:10.1385/0-

74. Zhang X, Paganelli FL, Bierschenk D, Kuipers A, Bonten MJ, Willems RJ, van Schaik W. 2012. Genome-wide identification of ampicillin resistance determinants in Enterococcus faecium.

75. Rice LB, Carias LL, Donskey CL, Rudin SD. 1998. Transferable, plasmid-mediated VanB-type glycopeptide resistance in Enterococcus faecium. Antimicrob Agents Chemother 42:963-4.

76. Mihara T, Nishimura Y, Shimizu Y, Nishiyama H, Yoshikawa G, Uehara H, Hingamp P, Goto S, Ogata H. 2016. Linking virus genomes with host taxonomy. Viruses 8:66. doi:10.3390/v8030066.

Figure Legends.

Figure 1. Genome organization and morphogenesis of three previously uncharacterized $E$.

faecium phages. Whole genome sequencing reveals a modular functional organization of phage version 2.0 and by the Texas A\&M Center for Phage Therapy structural analysis workflow version 2020.01. Colored open reading frames correspond to functional prediction. Beneath the phage genome maps, TEM shows phage 9181, 9183 and 9184 are non-contractile tailed Siphoviridae. The E. faecium 1004 host strain for phage 9181 is $E$. faecium Com12. The host strain for phage 9183 and 9184 is $E$. 
1006 Figure 2. Comparative genomic analysis identifies two novel enterococcal phage orthoclusters.

1007 A comparative genome analysis was performed using OrthoMCL as described previously by Bolocan et 1008 al. (16). A phylogenetic proteomic tree was constructed from the OrthoMCL matrix using the Manhattan 1009 distance metric and hierarchical clustering using an average linkage with 1000 iterations. Ninety-nine 1010 enterococcal phage genomes available from NCBI were used for comparison to E. faecium phages 10119181,9183 , and 9184 (highlighted in red, emphasized by red arrows). Distinct phage orthoclusters are 1012 represented by colored boxes. Roman numerals to the right of the shaded boxes signify the phage 1013 orthocluster number. Phage orthocluster morphology is indicated by calipers (if known) or an asterisk 1014 symbol (if unknown) to the right of the roman numerals.

Figure 3. E. faecium phages demonstrate broad and narrow host ranges and plaque most from a phage susceptibility assay. (A) Indicates host range for a collection of laboratory strains. (B) Indicates the host range for a collection of clinical isolates provided by the clinical microbiology lab at utilized for phage propagation. Efficiency of plating assay shows that phage 9181 (C) and 9184 (D) plaque most efficiently on their laboratory host strains. Data represent the average of three replicates \pm the standard deviation. ${ }^{*}, P<0.05$ and ${ }^{* *}, P<0.01$ by unpaired Student's t-test.

Figure 4. E. faecium elicits a robust resistance phenotype to phage 9181 and 9183 , but variable resistance to phage 9184. Representative phage resistant strains raised against phages 9181 (A), $9183(\mathrm{~B})$, and $9184(\mathrm{C})$. Data show phage susceptibility assays and associated bacterial enumeration 
1033 and phage 9183 resistant $(B)$ strains exhibit $\geq 4$-log of survival in the presence of phages compared to 1034 the parental E. faecium Com12 and 1,141,733 (733) strains, respectively. Phage 9184 resistant strains 1035 (C) exhibit diverse resistance strength characterized by weak (84R2) and strong (84R6) resistance 1036 phenotypes. The dotted line indicates the spontaneous mutation threshold of wild type E. faecium, 1037 which is defined as the mean CFU per $\mathrm{ml}$ at which spontaneous phage resistance is observed for the 1038 wild type host strain of each phage.

Figure 5. A diverse assortment of mutations confers phage resistance in E. faecium. (A) Protein secondary structure of E. faecium Com12 SagA, consisting of an N-terminus coiled-coil domain (residues 18-242) and C-terminus NIpC_P60 peptidoglycan hydrolase domain (residues 393-520). Displayed above the protein structure are colored lollipops denoting the site of mutations within NIpC_P60 domain of phage 9181-resistant mutants. Inside and below the protein structure are colored one letter amino acid abbreviations and lines, respectively, corresponding to key active site (red) and peptidoglycan clamp residues (teal) of the NIpC_P60 domain. Abbreviations: W, tryptophan; C, 1047 Cysteine; H, Histidine; G, Glycine; D, Aspartate; L, Leucine; Y, Tyrosine; V, Valine. (B) Capsule locus 1048 mutations are detected in a tyrosine kinase (wze), aminotransferase (efsg_rs08090), wzy 1049 (efsg_rs08105), and nucleotide sugar dehydrogenase (efsg_rs08120) of phage 9184-resistant mutants. 1050 Arrows indicate open reading frames. Arrow colors correspond to colored boxes (figure bottom left) 1051 indicate predicted open reading frame function (17). Colored lollipops above the arrows corresponding 1052 to colored dots (figure bottom right) indicate the mutational type. E. faecium 1,141,733 locus tags are 1053 angled below the arrows. (C) A missense mutation is found within a predicted arginine-aspartate1054 aspartate protein ( $r d d$; black arrow) of one phage 9184-resistant mutant (84R6) of E. faecium $10551,141,733 . r d d$ is flanked upstream by a predicted hypothetical protein (white arrow) and signal 1056 sequence peptidase A ( $s s p$; black arrow) and downstream by another hypothetical protein (white 1057 arrow). E. faecium 1,141,733 locus tags are angled below the arrows. (D) Mutations in predicted 1058 teichoic acid biosynthesis genes (epaR and epaX) are identified in phage 9183-resistant mutants of $E$. 1059 faecium 1,141,733 (25). Arrow colors correspond to colored boxes (figure bottom left) indicate 
1060 predicted open reading frame function. Colored lollipops above the arrows corresponding to colored 1061 dots (figure bottom right) indicate the mutational type. E. faecium 1,141,733 locus tags are angled 1062 below the arrows. The brackets above the locus correspond the conserved (left) and variable (right) 1063 portions of the epa locus proposed to by Gueredal et al. to encode the machinery necessary for 1064 rhamnopolysaccharide synthesis and wall teichoic acid biosynthesis, respectively (25).

Figure 6. Mutation in the capsule and exopolysaccharide loci limit phage adsorption in $E$. $P<0.001 ;{ }^{* * *}, P<0.0001$ by unpaired Student's $t$ test. both phage and sub-inhibitory concentration of antibiotics (filled orange, grey and purple triangles or diamonds), or media alone (open black circles). Phage 9181 was used in experiments with E. faecium Com12, while phage 9183 was employed for experiments with 1,141,733. Phages 9181 (A) and 9183

\section{Supplemental Figure Legends}


1087

1088

1089

1090

1091

1092

1093

1094

1095

1096

1097

1098

1099

1100

1101

1102

1103

1104

1105

1106

1107

1108

1109

1110

1111

1112

1113

Figure S1. PCR screen for phage lysogeny in phage resistant mutants. A molecular weight marker with corresponding band sizes in base pairs (i.e. bp) is shown at the far left and right of each gel image. (A) PCR screen for phage 9181 lysin gene in E. faecium or phage 9181 genomic DNA. Lane numbers correspond to the following genomic DNA samples: 1) $81 \mathrm{R} 3,2) 81 \mathrm{R} 4$, 3) $81 \mathrm{R} 5,4)$ () $81 \mathrm{R} 6,5) 81 \mathrm{R} 7,6$ ) 81R8, 7) E. faecium Com12, 8) Phage 9181, 9) negative control. (B) PCR screen for phage 9183 integrase gene in E. faecium or phage 9183 genomic DNA. Lane numbers correspond to the following genomic DNA samples: 1) 83R1, 2) 83R2, 3) 83R3, 4) 83R4, 5) 83R5, 6) 83R6, 7) 83R7, 8) 83R8, 9) $E$. faecium 1,141,733, 10) Phage 9183, 11) negative control. (C) PCR screen for phage 9184 lysin gene in E. faecium or phage 9184 genomic DNA. Lane numbers correspond to the following genomic DNA samples: 1) 84R1, 2) 84R2, 3) 84R3, 4) 84R4, 5) 84R5, 6) 84R6, 7) 84R8, 8) E. faecium 1,141,733, 9) phage 9184,10$)$ negative control.

Figure S2. Enterococcus faecium phage orthoclusters. Phage protein coding sequence alignments were performed with nearest neighbors in VIP Tree $(71,76)$. Colored lines connecting genomes indicate percent protein identity along the length of each genome. (A) Phage 9183 demonstrates protein homology and similar genome organization to its nearest neighbor intra-orthocluster phages (phages VFW and VPE25). (B) Phage 9184 demonstrates proteome homology and similar genome organization to its nearest neighbor intra-orthocluster phages (phages vB EfaS-DELF1 and IME-EFm5). (C) Phage 9181 shows little to no protein homology to its nearest neighbor extra-orthocluster phages (phages EFC-1 and FLA4).

Figure S3. Phage resistant mutants of E. faecium following exposure to phages 9181,9183 and 9184. Phage $9181(\mathrm{~A}), 9183(\mathrm{~B})$, and $9184(\mathrm{C})$ susceptibility assays and associated bacterial enumeration of wild type and phage resistant mutants in the presence (white bars) or absence (black bars) of phage (A-F) from three independent experiments. Phage 9181 (A, D) and phage 9183 (B, E) resistant strains exhibit $\geq 5$-logs of survival versus E. faecium Com12 and 1,141,733 (i.e. 733), respectively. Phage $9184(\mathrm{C}, \mathrm{F})$ resistant strains exhibit a weak resistance phenotypes. The dotted line 
1114 indicates the spontaneous mutation threshold conferring phage resistance observed in the respective

1115 wild type host strain of each phage. The threshold was placed to aid in discriminating weak phage

1116 resistance phenotypes versus the parental strain.

1118 Figure S4. SagA is conserved in E. faecium Com12 and Com15 and SagA is expressed in sagA

1119 mutants. (A) Displayed is the BLASTP alignment of SagA between Com12 and Com15, showing 95\%

1120 similarity and strict conservation of peptidoglycan clamp (orange lettering) and active site residues (red

1121 lettering). Colored highlights indicate the location of amino acid changes detected in phage 9181

1122 resistant mutants (81R3 and 81R4 - green highlight, 81R5 - yellow highlight, 81R6 - blue highlight,

$112381 R 8$ - magenta highlight). Specific amino acid changes are noted below the alignment in parentheses

1124 next to their respective phage resistant mutant. (B) Growth of E. faecalis OG1RF, E. faecium Com15,

1125 Com12 (WT) and sagA mutants (81R3-6; 81R8) are similar in BHI, except for 81R6. (C,D) Displayed is

1126 the whole protein fraction (upper panel; Stain-Free) and Western Blot of SagA (lower panel; $\alpha$-SagA)

1127 taken from the exponential phase $\left(O D_{600} \sim 0.8\right)$ supernatants $(C)$ or cell pellets $(D)$ of $E$. faecalis

1128 OG1RF, E. faecium Com15, Com12 (WT), and sagA mutants (81R3-6; 81R8). Protein band sizes are

1129 demonstrated to the left of each panel in kilodaltons (kDa).

1131 Figure S5. Complementation restores phage susceptibility in phage resistant mutants.

1132 Bacterial enumeration from Phage 9181 (A and B), 9184 (C), and 9183 (D) phage susceptibility assays

1133 of wild type and phage resistant mutants complemented with their respective wild type allele or empty

1134 vector. Assays were performed in the presence (white bars) or absence (black bars) of phages from

1135 two independent experiments. The bars and error bars indicate the average and standard deviation

1136 from two independent experiments. The dotted line indicates the spontaneous mutation threshold

1137 conferring phage resistance observed in the respective wild type host strain of each phage.

Figure S6. Complementation restores phage adsorption in phage resistant mutants. Percentage

1140 phage adsorption of phage resistant mutants, complemented phage resistant mutants, or their parental 
1141 strains to Phage 9181 (A), 9183 (B), and 9184 (C). Parental and phage resistant mutants were

1142 complemented with the empty vector $(\mathrm{E} ; \mathrm{pLZ12a})$ and compared to their complemented phage resistant

1143 mutant strain. Data represent the mean percent adsorption and standard deviation from three

1144 independent experiments. ${ }^{*}, P<0.05$; ${ }^{* *}, P<0.001 ;{ }^{* * * *}, P<0.0001$; ns, non-significant by unpaired

\section{Student's $t$ test.}

1146 


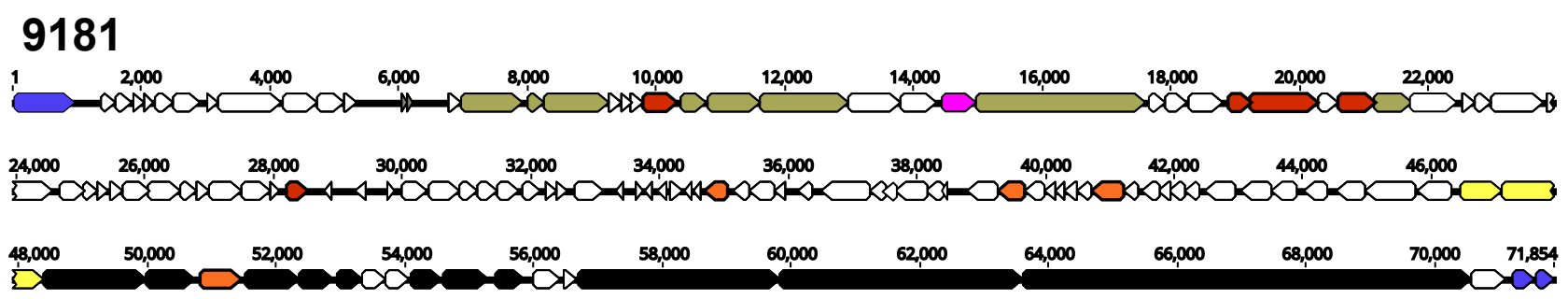

\section{3}

\section{1,854bp}
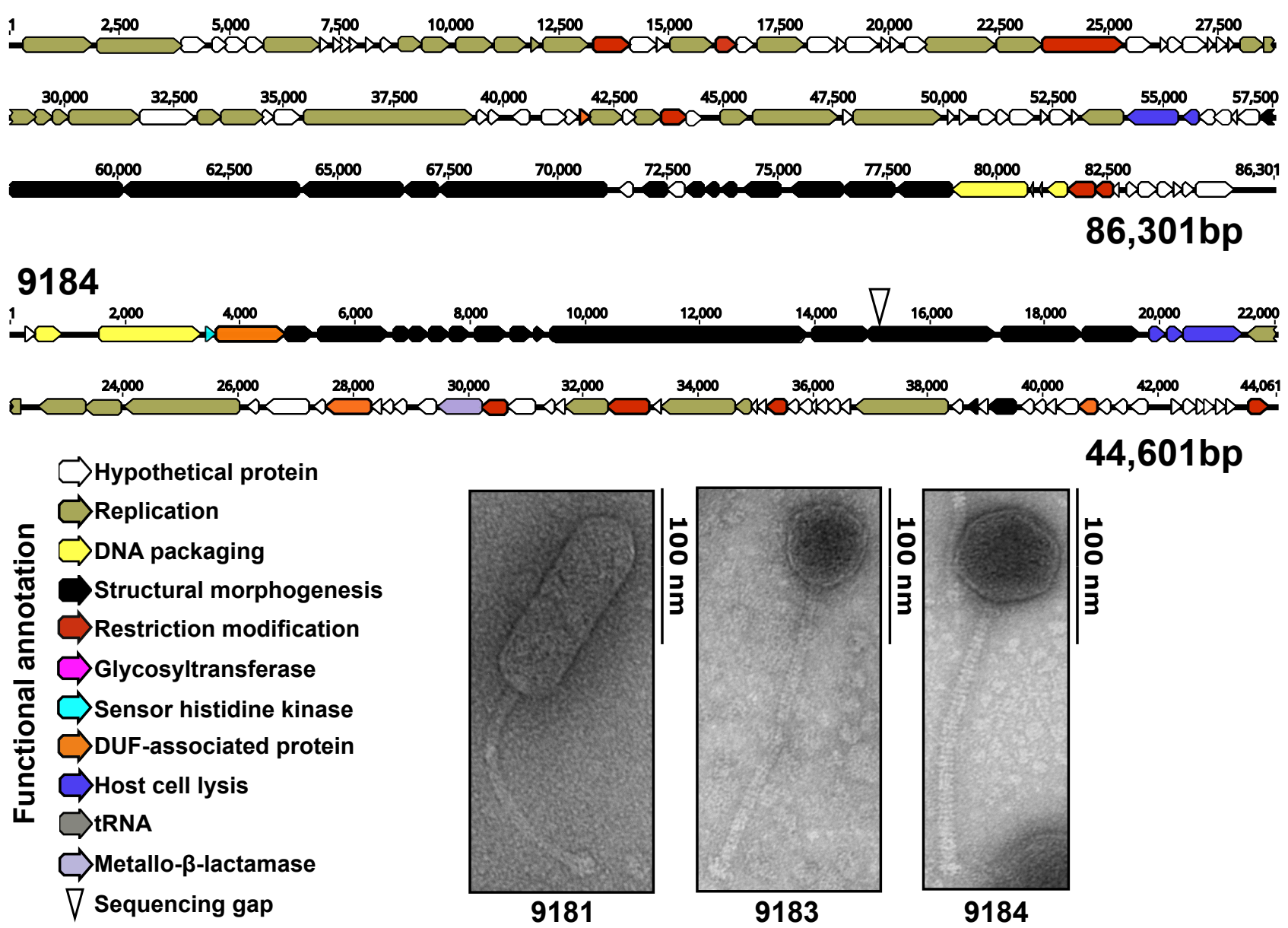

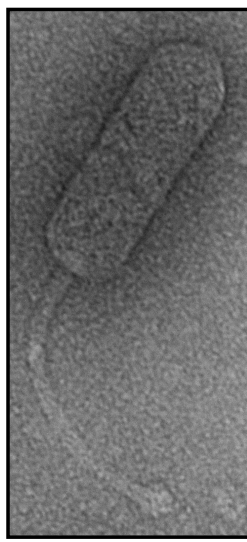

9181

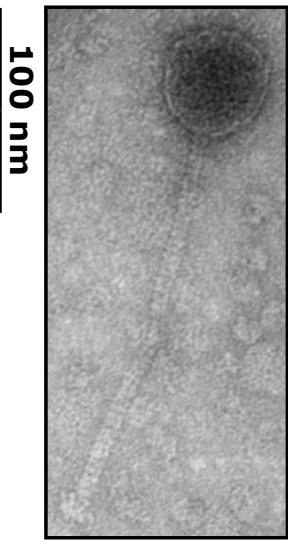

9183

44,601bp

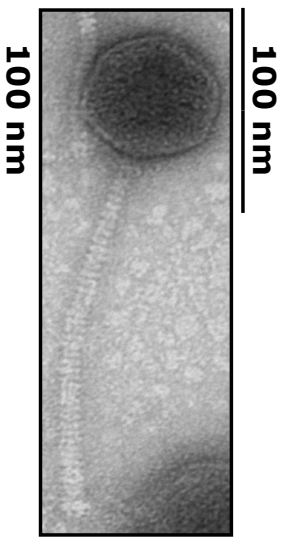

9184 
bioRxiv preprint doi: https://doi.org/10.1101/2020.09.22.309401; this version posted January 27, 2021. The copyrichlis

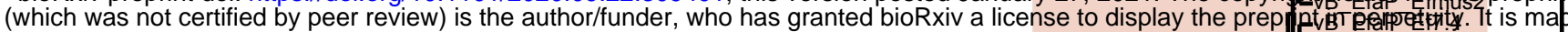
available under aCC-BY-NC-ND 4.0 International license.

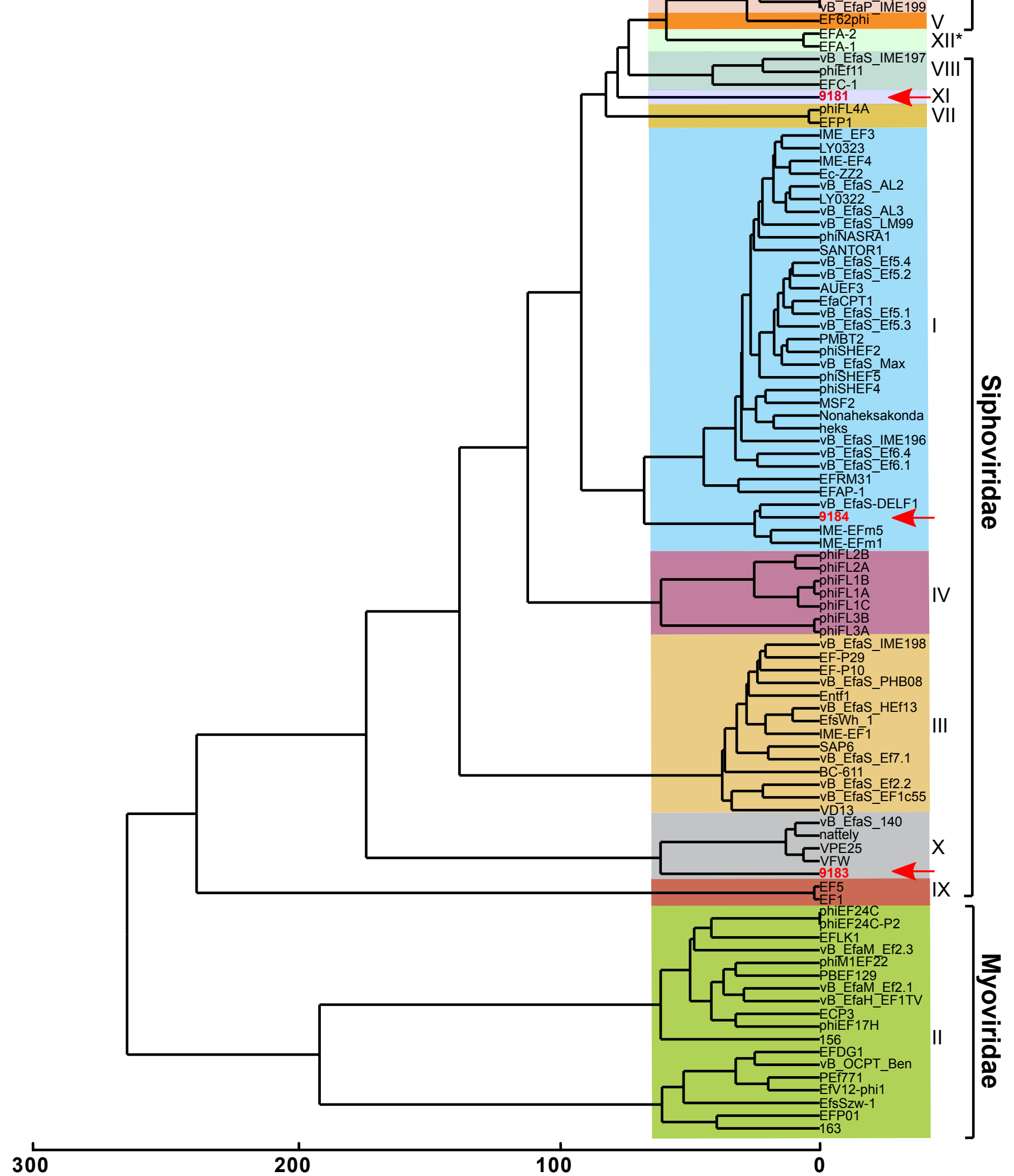


A

Dilution $\left(10^{x}\right)$

$\begin{array}{llllllll}-3 & -4 & -5 & -6 & -3 & -4 & -5 & -6\end{array}$

$81 R 3 \bigcirc$ \%

Com12
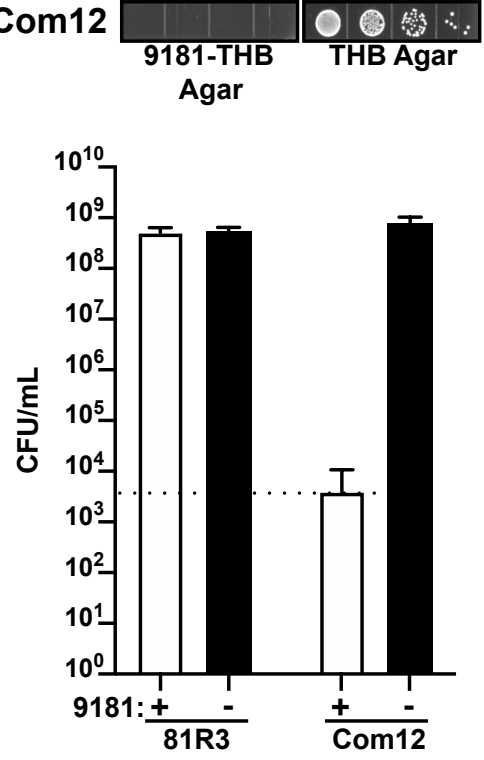

B
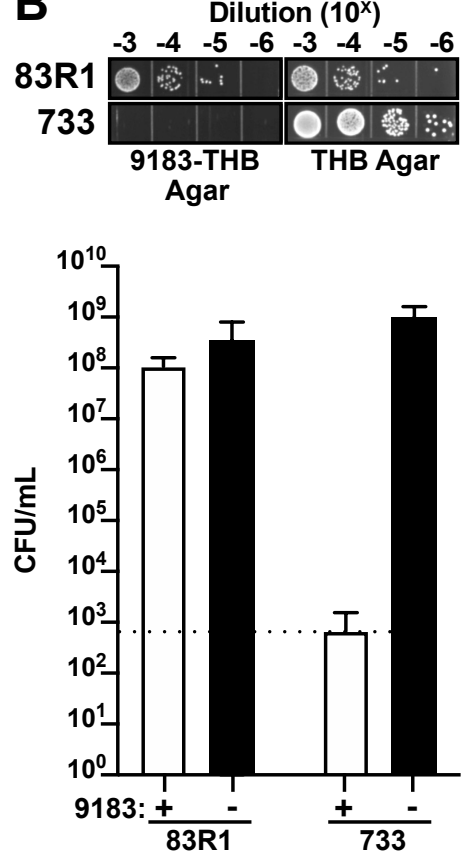

C
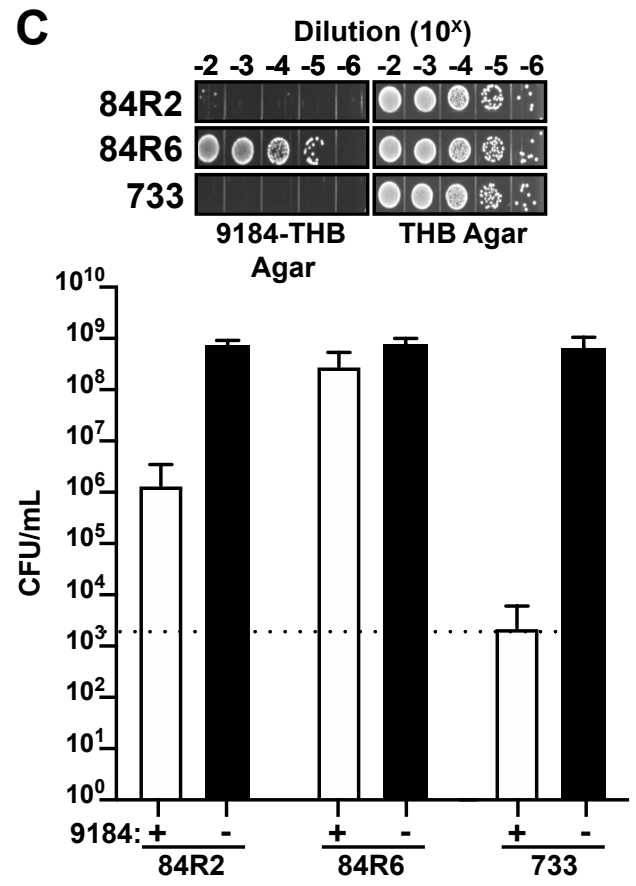

Figure 4 
bioRxiv preprint doi: https://doi. org/10.1101/2020.09.22.309401; this version posted January 27, 2021. The copyright holder for this preprint (which was not certified by peer review) is the author/funder, who has granted bioRxiv a license to display the preprint in perpetuity. It is made available under aCC-BY-NC-ND 4.0 International license.

A

\section{E. faecium Com12 SagA}

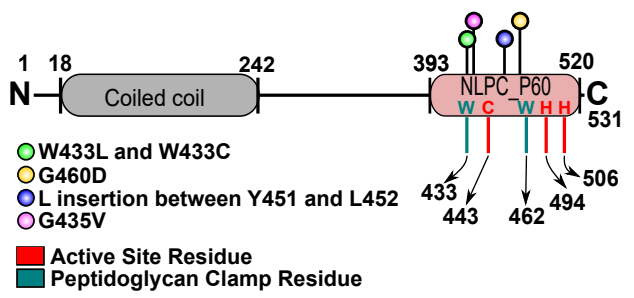

B

\section{E. faecium 1,141,733 capsule locus}

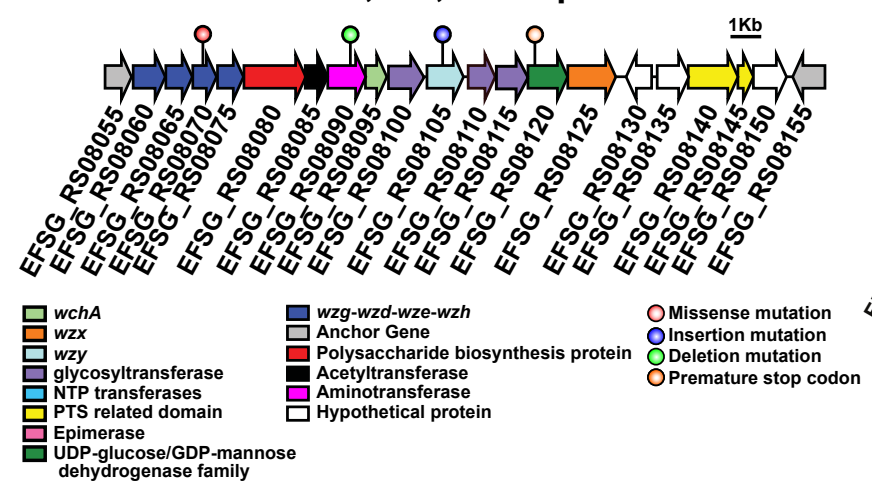

C E. faecium $1,141,733$ rdd locus

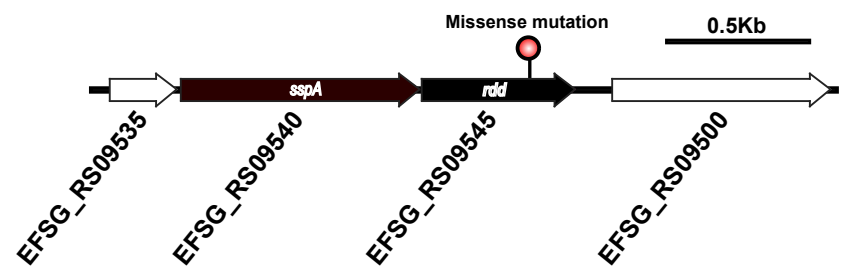

D E. faecium $1,141,733$ epa locus

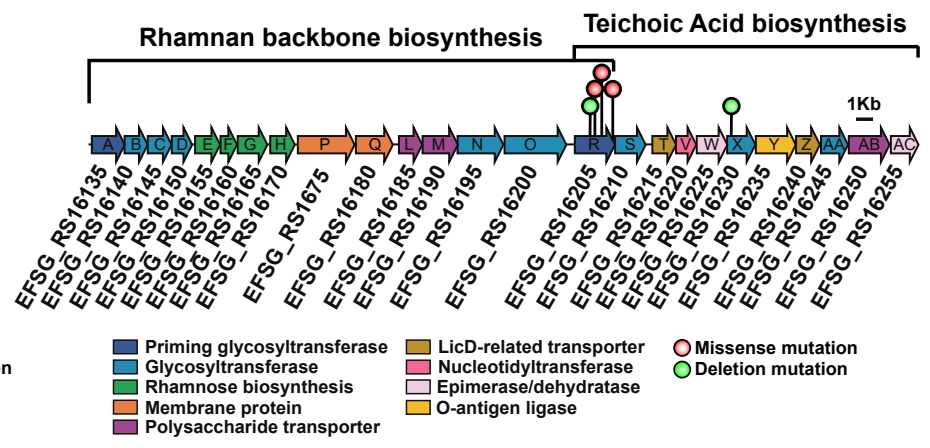



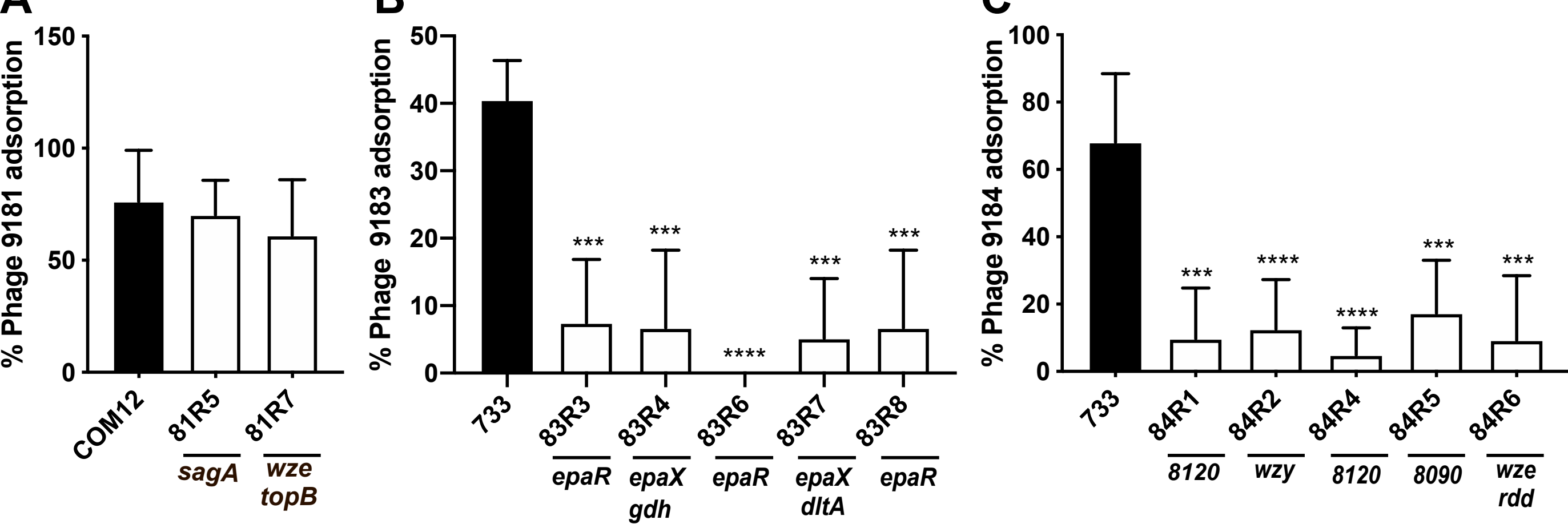


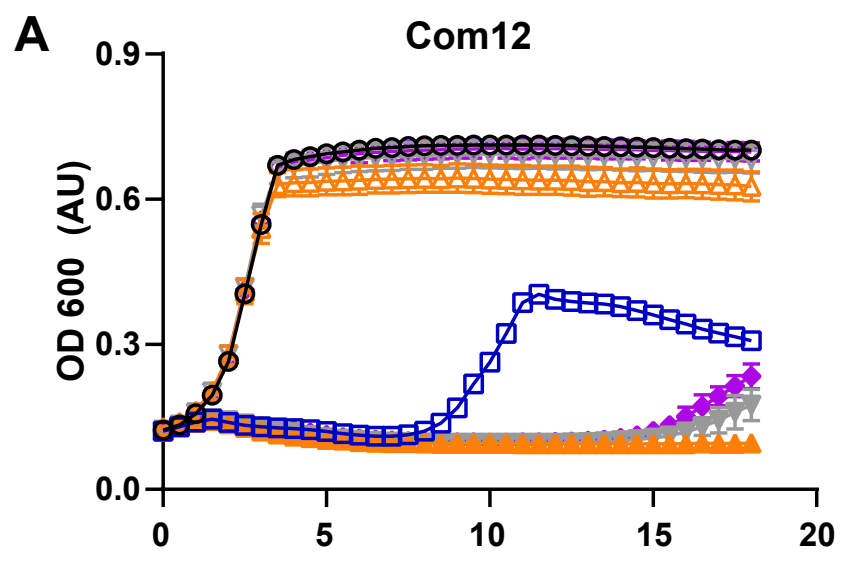

Hours

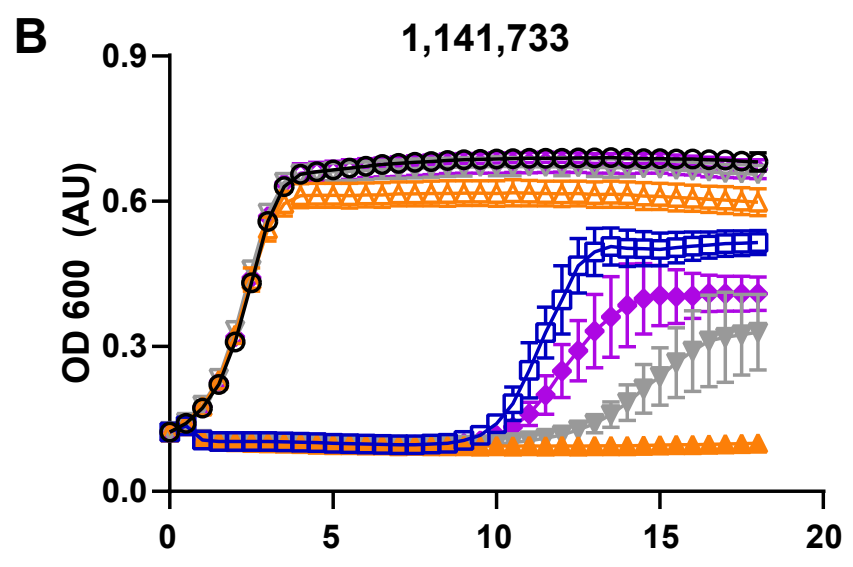

Hours

$$
\begin{aligned}
& \multimap \text { Untreated } \triangle \text { AMP }(1 \mu \mathrm{g} / \mathrm{mL}) \rightarrow \text { AMP }(0.25 \mu \mathrm{g} / \mathrm{mL}) \quad \rightarrow \text { AMP }(0.5 \mu \mathrm{g} / \mathrm{mL})+\text { Phage } \\
& \because \text { Phage } \rightarrow \text { AMP }(0.5 \mu \mathrm{g} / \mathrm{mL}) \approx \text { AMP }(1 \mu \mathrm{g} / \mathrm{mL})+\text { Phage } \multimap \text { AMP }(0.25 \mu \mathrm{g} / \mathrm{mL})+\text { Phage }
\end{aligned}
$$

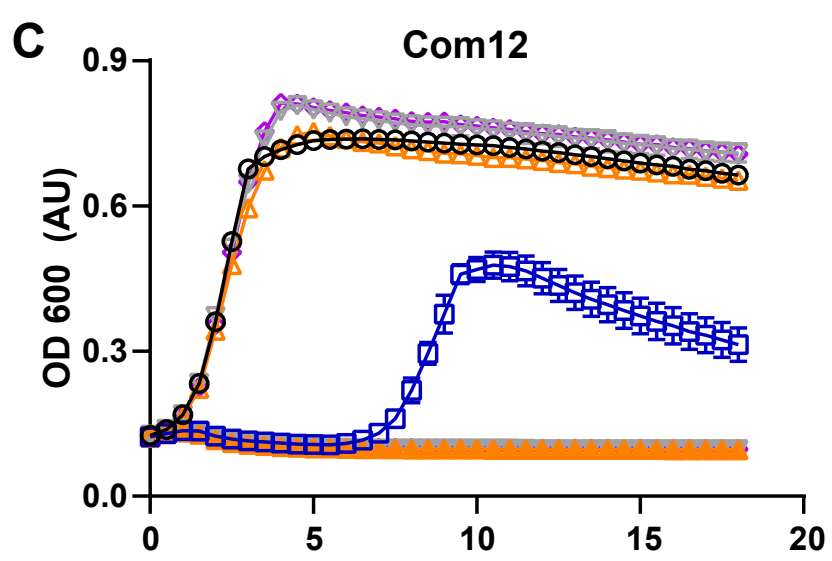

Hours

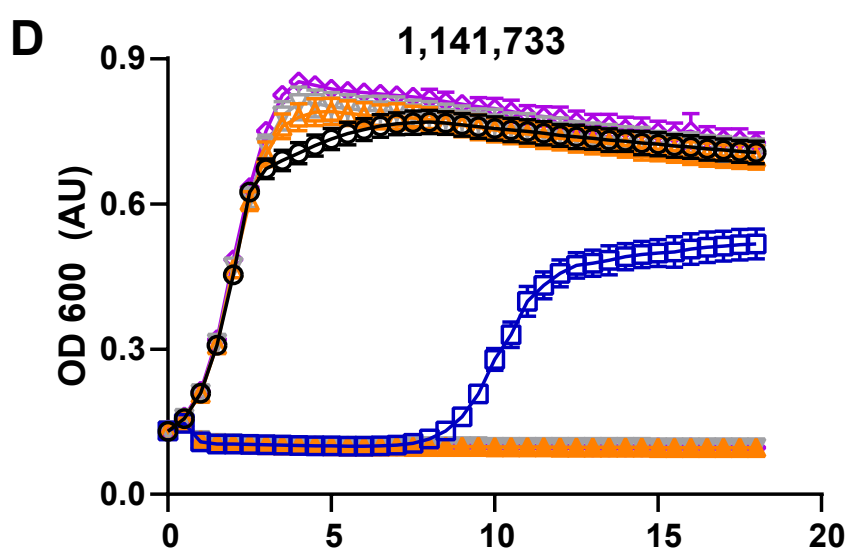

Hours

$$
\begin{aligned}
& \diamond \text { Untreated } \triangleleft \text { CTX }(1 \mu \mathrm{g} / \mathrm{mL}) \quad-\text { CTX }(0.25 \mu \mathrm{g} / \mathrm{mL}) \quad-\text { CTX }(0.5 \mu \mathrm{g} / \mathrm{mL})+\text { Phage } \\
& \because \text { Phage } \rightarrow \text { CTX }(0.5 \mu \mathrm{g} / \mathrm{mL}) \approx \text { CTX }(1 \mu \mathrm{g} / \mathrm{mL})+\text { Phage } \multimap \text { CTX }(0.25 \mu \mathrm{g} / \mathrm{mL})+\text { Phage }
\end{aligned}
$$

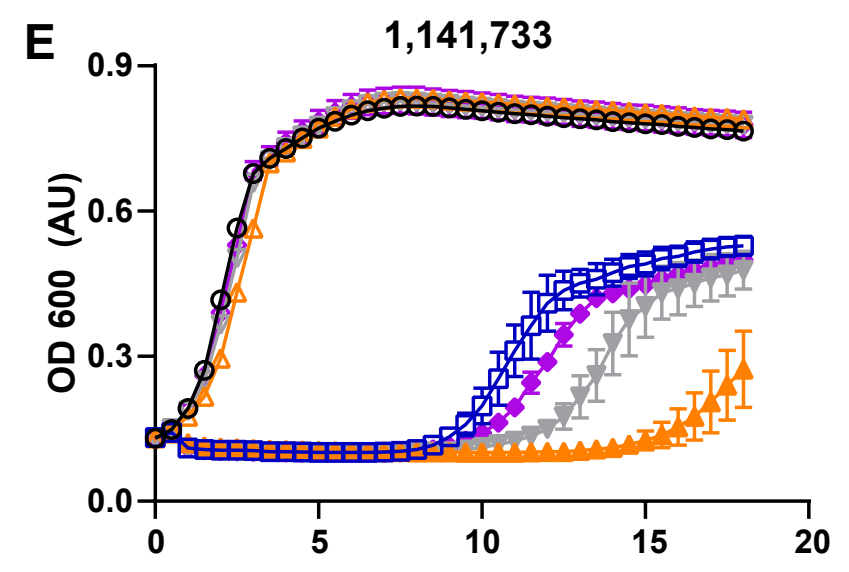

Hours

$$
\begin{aligned}
& \multimap \text { Untreated } \rightarrow \text { DAP }(4 \mu \mathrm{g} / \mathrm{mL}) \rightarrow \text { DAP }(1 \mu \mathrm{g} / \mathrm{mL}) \quad \rightarrow \text { DAP }(2 \mu \mathrm{g} / \mathrm{mL})+\text { Phage } \\
& \because \text { Phage } \rightarrow \text { DAP }(2 \mu \mathrm{g} / \mathrm{mL}) \approx \text { DAP }(4 \mu \mathrm{g} / \mathrm{mL})+\text { Phage } \curvearrowleft \text { DAP }(1 \mu \mathrm{g} / \mathrm{mL})+\text { Phage }
\end{aligned}
$$


Table 1. Phages, E. faecium host strain, and phage resistant mutants

\begin{tabular}{cccc}
\hline Phage & $\begin{array}{c}\text { E. faecium } \\
\text { host strain }\end{array}$ & $\begin{array}{c}\text { Phage } \\
\text { resistant mutants }\end{array}$ & $\begin{array}{c}\text { Number of Phage } \\
\text { Resistant mutants }\end{array}$ \\
\hline 9181 & Com12 & 81R3-R8 & 6 \\
\hline 9183 & $1,141,733$ & 83R1-R8 & 8 \\
\hline 9184 & $1,141,733$ & 84R1-R6, 84R8 & 7 \\
\hline
\end{tabular}

